\title{
Sorting of the Vesicular GABA Transporter to Functional Vesicle Pools by an Atypical Dileucine-like Motif
}

\author{
Magda S. Santos, ${ }^{1}$ C. Kevin Park, ${ }^{1}$ Sarah M. Foss, ${ }^{1,2}$ Haiyan Li, ${ }^{1}$ and Susan M. Voglmaier ${ }^{1}$ \\ ${ }^{1}$ Department of Psychiatry, and ${ }^{2}$ Graduate Program in Cell Biology, University of California, San Francisco, School of Medicine, San Francisco, California \\ 94143-0984
}

Increasing evidence indicates that individual synaptic vesicle proteins may use different signals, endocytic adaptors, and trafficking pathways for sorting to distinct pools of synaptic vesicles. Here, we report the identification of a unique amino acid motif in the vesicular GABA transporter (VGAT) that controls its synaptic localization and activity-dependent recycling. Mutational analysis of this atypical dileucine-like motif in rat VGAT indicates that the transporter recycles by interacting with the clathrin adaptor protein AP-2. However, mutation of a single acidic residue upstream of the dileucine-like motif leads to a shift to an AP-3-dependent trafficking pathway that preferentially targets the transporter to the readily releasable and recycling pool of vesicles. Real-time imaging with a VGAT-pHluorin fusion provides a useful approach to explore how unique sorting sequences target individual proteins to synaptic vesicles with distinct functional properties.

\section{Introduction}

How proteins are sorted to synaptic vesicles (SVs) has been a long-standing question in cell biology. At the nerve terminal, synaptic vesicles undergo exocytosis and then reform through endocytic events. The retrieval of the proper complement of vesicle proteins is essential, but the local sorting events that mediate it are not well understood (Santos et al., 2009). Sorting may depend on factors intrinsic to the protein, such as trafficking motifs encoded in the protein sequence that promote interaction with the endocytic machinery. For example, the vesicular monoamine transporters (VMATs) and acetylcholine transporter (VAChT) contain dileucine motifs that are important for sorting and endocytosis (Tan et al., 1998; Santos et al., 2001). Efficient recycling of the vesicular glutamate transporter VGLUT1 is mediated by both a dileucine-like motif and an additional polyproline domain that binds to the endocytic proteins, endophilins (Voglmaier et al., 2006). These motifs may confer different recycling properties that could influence synaptic function. Differences in the trafficking motifs of individual SV proteins could target them to distinct recycling pathways resulting in different rates of recycling, deliv-

Received Jan. 23, 2013; revised April 29, 2013; accepted May 13, 2013.

Author contributions: M.S.S. and S.M.V. designed research; M.S.S., C.K.P., S.M.F., H.L., and S.M.V. performed research; M.S.S., C.K.P., and S.M.V. analyzed data; M.S.S., H.L., and S.M.V. wrote the paper.

This work was supported by grants from the NIMH, the Staglin Family/International Mental Health Research Organization, the Brain and Behavior Research Foundation (NARSAD), and the UCSF Program for Breakthrough Biomedical Research, Dean's Office, and Resource Allocation Program. We thank Robert Edwards (UCSF) for generous gifts of constructs and antibodies and for helpful discussions, Timothy Ryan (Cornell University) for the gift of shRNA-resistant $\mu 2$ construct, Volker Haucke (Leibniz Institut für Molekulare Pharmakologie) for stonin 2 antibody, and Rebecca Seal (University of Pittsburg) for critical reading of the manuscript. We also thank Ursula Pieper from the laboratory of Andrej Sali (UCSF) and Zachary Schwartz for assistance with molecular modeling.

The authors declare no competing financial interests.

Correspondence should be addressed to Dr Susan M. Voglmaier, Department of Psychiatry, University of California School of Medicine, 401 Parnassus Avenue, LPPI-A101, San Francisco, CA 94143-0984. E-mail: Susan.Voglmaier@ucsf.edu.

DOI:10.1523/JNEUROSCI.0329-13.2013

Copyright $\odot 2013$ the authors $\quad 0270-6474 / 13 / 3310634-12 \$ 15.00 / 0$ ery to different vesicle pools, or molecular heterogeneity of SVs that could determine their functional characteristics (Morgenthaler et al., 2003; Salazar et al., 2004; Voglmaier and Edwards, 2007; Hua et al., 2011a; Lavoie et al., 2011; Raingo et al., 2012; Ramirez et al., 2012).

Inhibitory neurotransmission depends upon the recycling of GABA back into the nerve terminal after release. The transmitter is then repackaged into SVs by VGAT, also known as vesicular inhibitory amino acid transporter (VIAAT) (Fykse and Fonnum, 1988; Hell et al., 1988; Burger et al., 1991; McIntire et al., 1997; Sagne et al., 1997). Interestingly, recent work has shown that the VGAT N-terminus is cleaved at residues 52 and 60 under exocytotoxic conditions, giving rise to a truncated form of the transporter. Truncated VGAT is no longer targeted to synaptic sites, but is evenly distributed along neuronal processes (Gomes et al., 2011). This suggests that all the intrinsic signals responsible for targeting VGAT to SVs reside in its N-terminus, making this an ideal system to understand how unique sorting sequences target individual SV proteins to pathways with different rates or destinations.

\section{Materials and Methods}

\section{Reagents}

Bafilomycin 1A was obtained from Calbiochem. CNQX (6-cyano7 nitroquinoxaline-2,3-dione and CPP (3-(2-carboxypiperazin-4-yl) propyl-1-phosphonic acid) were purchased from Tocris Bioscience. FM4-64 and FM5-95 were obtained from Biotium. Brefeldin A was purchased from LC Laboratories. Antibodies against AP $1 \gamma, \mathrm{AP} 2 \alpha, \beta$-NAP, and AP180 were purchased from BD Bioscience. Anti-AP- $3 \delta$ antibody was from the Developmental Studies Hybridoma Bank (University of Iowa). Antibodies against $\alpha$-tubulin and transferrin receptor were from EMD Millipore. Antibody against stonin 2 was a gift from Volker Haucke (Leibniz Institut für Molekulare Pharmakologie) and also purchased from Sigma-Aldrich. Secondary antibodies conjugated to FITC, Cy3, or Cy5 were from Jackson ImmunoResearch. Secondary antibodies conjugated to HRP were from GE Healthcare Life Sciences. All other chemicals 
were from Sigma-Aldrich. Cell culture reagents were from Life Technologies unless otherwise noted.

\section{Molecular biology}

Rat VGAT and GST-VGAT N-terminus cDNAs were gifts of R. Edwards, University of California San Francisco (UCSF). VGAT-pHluorin was constructed by inserting the pHluorin cDNA at the luminal C-terminus of VGAT, preceded by TGG using standard molecular biology procedures. For transfection in mammalian cells, cDNAs were subcloned into pCAGGS for expression under the control of the modified chicken actin promoter. For GST-fusion recombinant protein expression, VGAT $\mathrm{N}$-terminal constructs were subcloned into pGEX vectors (GE Healthcare Life Sciences). Lentiviral constructs expressing shRNA to rat AP-2 $\mu 2$ (5'-GTGGATGCCTTTCGCGTCA-3') (Kim and Ryan, 2009) or rat AP-3 $\delta 1$ (5'-CATGGATCATGACCAAGAA-3') (Asensio et al., 2010) were made in a pFHUBW vector (gift from R. Edwards, UCSF). The shRNA-resistant $\mu 2$ cDNA was a gift from T. Ryan (Cornell University). The shRNA-resistant $\delta 1$ construct was generated by introducing a silent mutation to the AP- $3 \delta 1$ target sequence: $5^{\prime}$-CATGGATCACGACCAAG AA-3'. Both shRNA-resistant cDNAs were subcloned into pCAGGSIRES2-mCherry.

Production of recombinant lentiviruses. Lentiviruses were produced in HEK293T cells by cotransfection of pFHUBW transfer vector and two packaging plasmids (pVSV-G and psPAX2) using Fugene HD. Cells were transfected and grown in UltraCULTURE serum-free media (Lonza) supplemented with $1 \mathrm{~mm}$ sodium pyruvate, $0.075 \%$ sodium bicarbonate, and $2 \mathrm{~mm}$ GlutaMax. Approximately $16 \mathrm{~h}$ posttransfection, $10 \mathrm{~mm}$ sodium butyrate was added to the culture media. Culture media containing lentivirus was collected $\sim 40 \mathrm{~h}$ after transfection and viral particles concentrated by centrifugation through a $20 \%$ sucrose/PBS-CMF cushion at $80,000 \times g$ for $2 \mathrm{~h}$. Viral particles were then resuspended in neuronal culture media supplemented with $4 \mathrm{mg} / \mathrm{ml}$ polybrene (hexadimethrine bromide).

RNA interference knockdown. To confirm specific knockdown of AP-2 and AP-3, rat hippocampal neurons were infected at $7 \mathrm{~d}$ in vitro (DIV), and harvested at 14 DIV. Neurons were lysed in $100 \mathrm{~mm}$ Tris-HCl, $\mathrm{pH}$ 7.5, $150 \mathrm{~mm} \mathrm{NaCl}, 1 \mathrm{~mm}$ EGTA, and 1\% Triton X-100 containing pro-

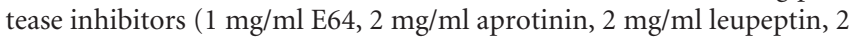
$\mathrm{mg} / \mathrm{ml}$ pepstatin, and $20 \mathrm{mg} / \mathrm{ml} \mathrm{PMSF}$ ). A postnuclear supernatant was prepared by centrifugation at $2500 \times g$ for $5 \mathrm{~min}$. AP-1, AP-2, and AP-3 were detected by anti-adaptin $\gamma, \alpha$, or $\delta$. For immunoblotting, $\sim 25 \mu \mathrm{g}$ of protein were separated by SDS-PAGE and transferred to PVDF membrane (Immobilon-P, Millipore) and probed with anti-adaptin $\gamma(1$ : $500)$, anti-adaptin $\alpha$ (1:1000), or anti-adaptin $\delta$ (1:250). Quantifications were performed with ImageJ (http://rsbweb.nih.gov/ij/), using $\alpha$-tubulin to normalize the signal.

\section{GST pull-downs}

Extracts from rat brain were solubilized in $100 \mathrm{~mm}$ Tris- $\mathrm{HCl}, \mathrm{pH}$ 7.5, 150 mM NaCl, 1 mm EGTA, and 1\% Triton X-100 containing protease inhibitors $(1 \mathrm{mg} / \mathrm{ml} \mathrm{E} 64,2 \mathrm{mg} / \mathrm{ml}$ aprotinin, $2 \mathrm{mg} / \mathrm{ml}$ leupeptin, $2 \mathrm{mg} / \mathrm{ml}$ pepstatin, and $20 \mathrm{mg} / \mathrm{ml}$ PMSF), sedimented at 20,000 $\times \mathrm{g}$ for $45 \mathrm{~min}$ at $4^{\circ} \mathrm{C}$, and the supernatant $(\sim 400 \mathrm{mg}$ total protein) incubated with $200 \mu \mathrm{g}$ of GST fusion proteins immobilized on glutathione-Sepharose at $4^{\circ} \mathrm{C}$ for $2 \mathrm{~h}$. After pelleting, the beads were washed and bound protein detected by immunoblot analysis using mouse monoclonal anti-adaptin $\gamma(1: 500)$, anti-adaptin $\alpha$ (1:1000), $\beta$-NAP (1:250), AP180 (1:500), or stonin 2 (1: $500)$. ImageJ was used to determine the intensity of bands using the intensity of the respective fusion protein loaded on the same lane (revealed by Ponceau-staining) to normalize the signal.

\section{Cell culture, transfection, and immunofluorescence}

HEK293 cells were grown in DME H-21 medium supplemented with $10 \%$ fetal bovine serum (FBS) and $1 \times$ pen $/$ strep at $37^{\circ} \mathrm{C}$ in $5 \% \mathrm{CO}_{2}$. Transient transfection was performed using Lipofectamine (Life Technologies) according to the manufacturer's instructions. For immunofluorescence, cells were fixed in 4\% PFA for $20 \mathrm{~min}$, permeabilized, blocked in PBS containing $0.1 \%$ Triton X-100 and 5\% cosmic calf serum, and stained with rabbit anti-VGAT (gift from R. Edwards, UCSF), and mouse anti-transferrin receptor, followed by appropriate secondary antibodies conjugated to FITC, Cy3, or Cy5. Images were acquired on a QuantEM CCD camera (Photometrics).

\section{Primary neuronal culture and immunofluorescence}

All work with animals was conducted under the supervision of the Institutional Care and Use Committee of the University of California, San Francisco. Hippocampi or striata from embryonic day 18-20 rats of either sex were dissociated as described previously (Li et al., 2005), and neurons transfected using a SCN Nucleofector kit (Lonza). Transfected neurons were infected with knockdown constructs at DIV 7. AP-3 knockdown experiments and analysis were performed blind with respect to whether neurons were infected with empty vector-containing or shRNA-containing virus. Dissociated neurons were plated onto coverslips coated with poly-L-lysine and laminin and subsequently maintained in neurobasal media supplemented with $1 \%$ heat inactivated FBS, $2 \%$ Neuro Mix (PAA), $2 \mathrm{~mm}$ GlutaMax, $15 \mathrm{~mm} \mathrm{NaCl}$, and $10 \mu \mathrm{g} / \mathrm{ml}$ primocin (Lonza) and imaged at DIV 14-16. 5-Fluoro-2'-deoxyuridine (10 $\mu \mathrm{M}$ final conc) was added at DIV 3-5 as a mitotic inhibitor to control glial growth. For immunostaining, cells were fixed in 4\% PFA for $15 \mathrm{~min}$, permeabilized, and blocked in PBS containing $0.1 \%$ Triton X-100 and $5 \%$ cosmic calf serum, and then stained with rabbit anti-VGLUT1 (gift from R. Edwards, UCSF), followed by appropriate secondary antibodies conjugated to FITC, Cy3, or Cy5. Cells were imaged using confocal laser microscopy.

\section{Live cell imaging}

Live cell imaging was performed essentially as described previously (Voglmaier et al., 2006). Coverslips with transfected neurons were mounted in a rapid switching, laminar-flow perfusion and stimulation chamber (Warner Instruments) on an inverted epifluorescence microscope (Nikon) and imaged at room temperature using a $63 \times$ oil objective $(\mathrm{NA}=1.4)$. Cells were imaged in modified Tyrode's solution (in mM: 119 $\mathrm{NaCl}, 10$ HEPES-NaOH, pH 7.4, 30 glucose, $2.5 \mathrm{KCl}, 2 \mathrm{CaCl}_{2}, 2 \mathrm{MgCl}_{2}$ ) containing $10 \mu \mathrm{M}$ each of the glutamate receptor antagonists CPP and CNQX. For readily releasable pool of vesicles (RRP) experiments, calcium concentration was increased to $4 \mathrm{~mm}$ (and $\mathrm{NaCl}$ decreased to 117 $\mathrm{mm}$ ), or kept at $2 \mathrm{~mm}$. Buffer containing $50 \mathrm{~mm} \mathrm{NH}_{4} \mathrm{Cl}$ was prepared by decreasing $\mathrm{NaCl}$. Tyrode's solution at $\mathrm{pH} 5.5$ was prepared by replacing HEPES with MES. Hypertonic sucrose was prepared by adding $300 \mathrm{~mm}$ sucrose to modified Tyrode's solution. Action potentials were elicited using an A310 Accupulser (WPI) at $10 \mathrm{~Hz}, 30 \mathrm{~Hz}$, or $100 \mathrm{~Hz}$ with $1 \mathrm{~ms}$ bipolar current pulses through platinum-iridium electrodes, to yield fields of 5-10 V/cm across the chamber (Voglmaier et al., 2006). Cells were illuminated using a Xenon lamp (Sutter Instruments) with either a $470 / 40 \mathrm{~nm}$ excitation and a 525/50 nm emission filter (for GFP), or a 470/40 $\mathrm{nm}$ excitation and 630/75 nm (for FM4-64 and FM5-95) emission filters (Chroma). Images were acquired on a QuantEM CCD camera (Photometrics) with EM gain at 500, exposing each fluorophore for 200 ms for images collected every 1-3 s. Shutter and camera were controlled by MetaMorph software (Molecular Devices). To measure exocytosis alone, cultures were incubated in modified Tyrode's medium containing $0.5-1 \mu \mathrm{M}$ bafilomycin A for $30 \mathrm{~s}$ before imaging in the same medium. To assess exocytosis with FM4-64, the cultures were incubated in modified Tyrode's solution containing $15 \mu \mathrm{M}$ FM4-64 and stimulated at $10 \mathrm{~Hz}$ for $60 \mathrm{~s}$, followed by continued incubation in the same medium for an additional $60 \mathrm{~s}$. After extensive washing for 10-15 $\mathrm{min}$ at a rate of $6 \mathrm{ml} / \mathrm{min}$ in modified Tyrode's solution without FM4-64, the FM dye was unloaded by stimulation at $10 \mathrm{~Hz}$ for $90 \mathrm{~s}$. Transfected boutons were identified by visualization of VGAT-pH puncta in the presence of $50 \mathrm{mM} \mathrm{NH}_{4} \mathrm{Cl}$, with washout before FM4-64 loading. For measurement of recycling pool size, neurons were loaded with $10 \mu \mathrm{M}$ FM5-95 at $10 \mathrm{~Hz} 60 \mathrm{~s}$, and unloaded at $10 \mathrm{~Hz}$ for $120 \mathrm{~s}$. To block AP-1 and AP-3 pathways, cultures were pretreated in neurobasal media containing $10 \mu \mathrm{g} / \mathrm{ml}$ brefeldin A (BFA) for $30 \mathrm{~min}$ at $37^{\circ} \mathrm{C}$ before imaging in modified Tyrode's solution containing the same concentration of BFA. To quench surface fluorescence, neurons were imaged in Tyrode's solution at $\mathrm{pH}$ 5.5. 


\section{Data analysis}

The fluorescence of manually designated $4 \times 4$ pixel boxes centered over boutons was averaged, and the average fluorescence of three $4 \times 4$ pixel boxes without cellular elements was subtracted as background. Baseline values from the first 5 frames (before stimulation) were averaged $\left(\mathrm{F}_{0}\right)$, and the dynamics of fluorescence intensity expressed as fractional change $(\Delta \mathrm{F})$ over initial fluorescence. For normalized measurements, the average pHlourin fluorescence over individual boutons was normalized to either the peak fluorescence in each trace, or the total fluorescence as determined by application of modified Tyrode's solution containing 50 $\mathrm{mM} \mathrm{NH}_{4} \mathrm{Cl}$ to alkalinize all synaptic compartments. Fluorescence measurements from 20 to 100 boutons per coverslip were averaged and the means from 6 to 19 coverslips from at least two independent cultures were averaged. Protein surface fraction was estimated by first subtracting the average of five frames with Tyrode's solution at $\mathrm{pH} 5.5$ from the average of five frames in Tyrode's solution at $\mathrm{pH}$ 7.4, and then dividing by the total fluorescence, defined by fluorescence in the presence of $50 \mathrm{~mm}$ $\mathrm{NH}_{4} \mathrm{Cl}$. The initial rise of fluorescence and the decrease after stimulation were fit with single exponentials (GraphPad Prism). The rate of exocytosis is estimated from an exponential fit to the increase in VGAT-pH fluorescence during the initial $30 \mathrm{~s}$ of stimulation in the presence of bafilomycin. For measurements of endocytosis after stimulation, the time course of fluorescence decay at each bouton after the initial $3 \mathrm{~s}$ (Balaji et al., 2008) was fit with a single exponential. To calculate the proportion of VGAT-pH in the RRP by electrical stimulation, neurons were stimulated in the presence of bafilomycin and the first five frames after stimulation were averaged and normalized to the total fluorescence in the presence of $50 \mathrm{mM} \mathrm{NH} \mathrm{N}_{4} \mathrm{Cl}$. To calculate the proportion of VGAT-pH in the RRP by challenge with hypertonic sucrose, neurons were stimulated with Tyrode's solution containing $300 \mathrm{~mm}$ sucrose for $6 \mathrm{~s}$ in the presence of $1 \mu \mathrm{M}$ bafilomycin to prevent reacidification of the internalized vesicles, and imaged in the absence of sucrose (to avoid distortion by changes in refractive index) both before and after stimulation (Nemani et al., 2010). Data are presented as means \pm SEM. Significance of differences between groups was assessed by two-tailed, unpaired $t$ test or one-way ANOVA followed by Bonferroni's test at $p<$ 0.05 where appropriate.

\section{Results \\ Trafficking signals in the VGAT N-terminus}

Recent evidence suggests VGAT has nine transmembrane domains, with a cytosolic N-terminus and a luminal C-terminus (Martens et al., 2008). In contrast, the vesicular neurotransmitter transporters for acetylcholine, monoamines, and glutamate all have a putative topology of 12 transmembrane domains with cytosolic C-termini that contain trafficking signals (Fei et al., 2008). We compared the N-terminal amino acid sequence of VGAT with C-terminal sequences of VAChT, VMAT2, and VGLUT to find signals that could be important for VGAT trafficking (Fig. 1A). We considered $\mathrm{E}_{39} \mathrm{EAVGFA}_{45}$ as a potential trafficking signal because it resembles the consensus acidic dileucine motif sequence [E/D]XXXL[L/I/] present in VAChT, VMAT2, and VGLUTs, consisting of acidic residues at the -4 and -5 positions upstream of two hydrophobic residues. Dileucine motifs interact with clathrin adaptor proteins (APs) (Heilker et al., 1996; Kelly et al., 2008) and direct sorting of many transmembrane proteins (Bonifacino and Traub, 2003). Other putative motifs in the VGAT N-terminus include two dileucine-like pairs, $\mathrm{L}_{4} \mathrm{~L}_{5}$ and $\mathrm{I}_{62} \mathrm{~L}_{63}$, and a polyproline sequence, $\mathrm{P}_{91} \mathrm{LPP}_{94}$ (Fig. $1 B)$. As an initial screen to identify the structural determinants that regulate the subcellular localization of VGAT, we introduced alanine point mutations to generate $\mathrm{I}_{62} \mathrm{~L}_{63} / \mathrm{AA}, \mathrm{F}_{44} \mathrm{~A} / \mathrm{AA}$, and $\mathrm{P}_{91} \mathrm{P}_{94} / \mathrm{AA}$ (Fig. $1 B$ ). Mutants were expressed in HEK293 cells, which were labeled with antibodies against VGAT and the endocytic marker transferrin receptor. Replacement of residues $\mathrm{I}_{62} \mathrm{~L}_{63}$ or $\mathrm{P}_{91} \mathrm{P}_{94}$ with alanine does not perturb the steady-state localiza- tion of VGAT. Like WT VGAT, IL/AA, and PP/AA mutants exhibit a punctate distribution that overlaps with transferrin receptor (Fig. 1C). In contrast, replacement of $\mathrm{F}_{44}$ with alanine drastically alters the subcellular distribution of VGAT. Antibody staining of FA/AA VGAT is not punctate and exhibits limited overlap with transferrin receptor (Fig. 1C).

\section{Development of a VGAT-pHluorin optical reporter}

To further investigate the trafficking of VGAT in neurons, we developed a VGAT-pHluorin fusion (VGAT-pH; Fig. 2A). When expressed in predominantly glutamatergic hippocampal neurons, VGAT-pH exhibits a punctate distribution with accumulation at synapses, where it colocalizes with endogenous VGLUT1 (Fig. 2B). The fluorescence of VGAT-pH is quenched at the low pH of SVs (Fig. 2C). Exocytosis relieves this quenching, resulting in an increase in fluorescence (Fig. 2C). Endocytosis is reflected by a decrease in fluorescence of VGAT-pH, as internalized vesicles are rapidly reacidified (Miesenböck et al., 1998; Sankaranarayanan and Ryan, 2000) (Fig. 2C). Upon electrical stimulation at $10 \mathrm{~Hz}$ for $60 \mathrm{~s}$, exposure of VGAT-pH to the extracellular $\mathrm{pH}$ due to SV exocytosis is visualized as a rapid, calcium-dependent increase in fluorescence at individual boutons (Fig. 2D). After termination of the stimulus, the fluorescence of VGAT-pH decays with an exponential time course $(\tau=33.03 \pm 1.79 \mathrm{~s})$, reflecting endocytosis and reacidification of SVs (Fig. 2D). Activitydependent unloading of the styryl dye FM4-64 from SVs is not affected by expression of VGAT-pH, indicating that the tagged transporter does not perturb general features of the vesicle cycle (Fig. 2E). We next examined VGAT-pH recycling in inhibitory neurons using primary cultures of striatal neurons, which are predominantly GABAergic. Under identical stimulus conditions, no differences in VGAT-pH fluorescence dynamics between striatal and hippocampal neurons are observed (Fig. $2 F$ ). In agreement with these results, recent work has shown that the kinetics of endocytosis and acidification in the small population of inhibitory synapses in hippocampal neuronal cultures cannot be distinguished from those of the entire population (Hua et al., 2011 b). Moreover, an analysis of variation revealed no significant differences in the distribution of endocytosis rates between excitatory and inhibitory neurons (Armbruster and Ryan, 2011). Because the properties of VGAT-pH recycling are similar in excitatory and inhibitory neurons, subsequent experiments were performed in hippocampal cultures to allow use of standard protocols and expression of mutant forms of VGAT-pH in the absence of endogenous VGAT background.

To examine the role of the $\mathrm{F}_{44} \mathrm{~A}_{45}$ motif in neurons, we replaced $\mathrm{F}_{44}$ with alanine in VGAT- $\mathrm{pH}$. $\mathrm{F}_{44} \mathrm{~A}$ /AA mutation dramatically slows endocytosis of VGAT-pH after stimulation at $10 \mathrm{~Hz}$ for $60 \mathrm{~s}(\tau=86.88 \pm 7.37 \mathrm{~s})$ compared with wild-type (WT, $\tau=$ $33.03 \pm 1.79 \mathrm{~s})$, suggesting that this unconventional dileucinelike motif plays a physiological role in VGAT recycling (Fig. 3A). Studies to determine the role of dileucine motifs in membrane protein trafficking generally involve replacement of the hydrophobic residues with alanine to determine the role of such motifs. Notably, the endogenous dileucine-like motif in VGAT already encodes alanine. Therefore, we also mutated $\mathrm{F}_{44}$ and $\mathrm{A}_{45}$ to glycine (FA/GG) (Honing et al., 1998). Remarkably, the glycinebased mutations nearly abolish VGAT recycling from the plasma membrane. FA/GG VGAT-pH fluorescence exhibits a nonsynaptic distribution, which does not change with stimulation (Fig. $3 \mathrm{~B})$. In contrast, the analogous mutation of dileucine-like FV residues in VGLUT1-pH to GG has a milder effect on VGLUT1-pH localization, with a slight increase in cell surface expression in 


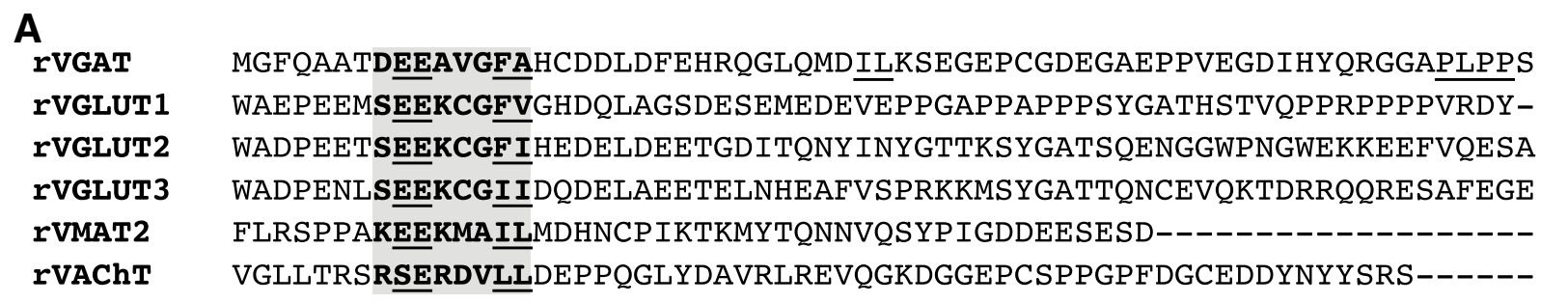

B rVGAT

MGFQAATDEEAVGFAHCDDLDFEHRQGLQMDILKSEGEPCGDEGAEPPVEGDIHYQRGGAPLPPS MGFQAATDEEAVGFAHCDDLDFEHRQGLQMDAAKSEGEPCGDEGAEPPVEGDIHYQRGGAPLPPS MGFQAATDEEAVGFAHCDDLDFEHRQGLQMDILKSEGEPCGDEGAEPPVEGDIHYQRGGAALPAS

F $44 \mathrm{~A} / \mathrm{AA}$

F 44 A $45 /$ GG MGFQAATDEEAVGAAHCDDLDFEHRQGLQMDILKSEGEPCGDEGAEPPVEGDIHYQRGGAPLPPS MGFQAATDEEAVGGGHCDDLDFEHRQGLQMDILKSEGEPCGDEGAEPPVEGDIHYQRGGAPLPPS $\mathrm{E}_{39 \mathrm{E}_{40} / \mathrm{GG}}$ $D_{38} / \mathrm{G}$ MGFQAATDGGAVGFAHCDDLDFEHRQGLQMDILKSEGEPCGDEGAEPPVEGDIHYQRGGAPLPPS MGFQAATGEEAVGFAHCDDLDFEHRQGLQMDILKSEGEPCGDEGAEPPVEGDIHYQRGGAPLPPS $\mathbf{E}_{39} \mathbf{E}_{40} \mathbf{F}$ 44A/4A MGFQAATDAAAVGAAHCDDLDFEHRQGLQMDILKSEGEPCGDEGAEPPVEGDIHYQRGGAPLPPS

C
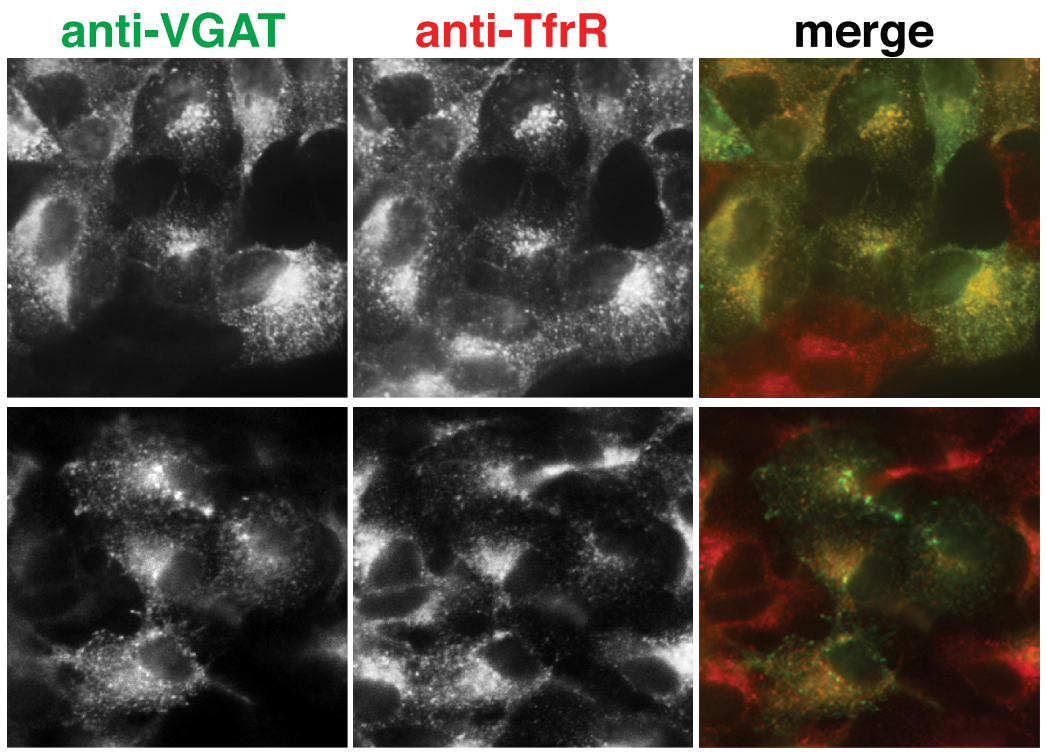

I62L63/AA

P91P94/AA
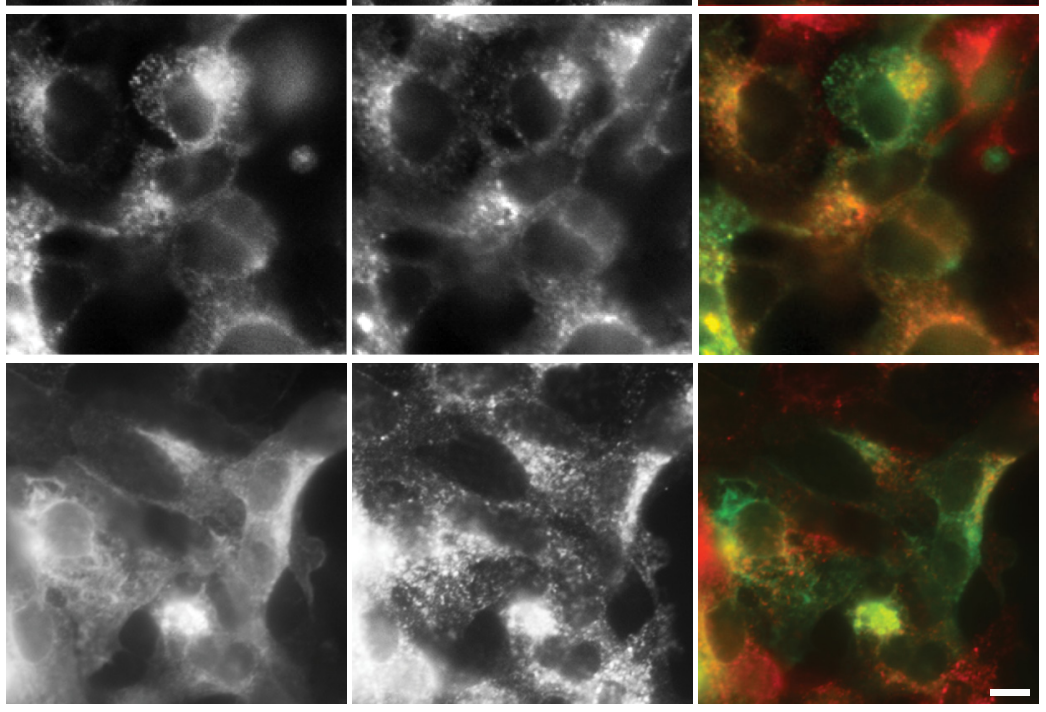

Figure 1. Mutagenesis screen of putative VGAT trafficking motifs. A, Alignment of putative targeting sequences in VGAT with similar sequences from other vesicular neurotransmitter transporters (bold, underlined). The dileucine-like sequences are in bold (Tan et al., 1998; Voglmaier et al., 2006). B, Mutations as indicated were used to map amino acid residues involved in VGAT trafficking. $C$, Mutation of $\mathrm{F}_{44}$ in a putative atypical dileucine motif to alanine $\left(\mathrm{F}_{44} \mathrm{~A} / \mathrm{AA}\right)$ results in increased VGAT localization at the plasma membrane (bottom), whereas mutation of a more typical dileucine pair $\left(I_{62} \mathrm{~L}_{63} / \mathrm{AA}\right)$ or a polyproline domain $\left(\mathrm{P}_{91} \mathrm{P}_{94} / \mathrm{AA}\right)$ does not affectVGAT localization (middle). HEK cells expressing the indicated VGAT mutants were fixed, permeabilized and stained with rabbit antibody to VGAT and mouse monoclonal antibody to transferrin receptor (TfR), followed by appropriate secondary antibodies. Acquisition parameters were identical for all conditions. Scale bar, $10 \mu \mathrm{m}$. 

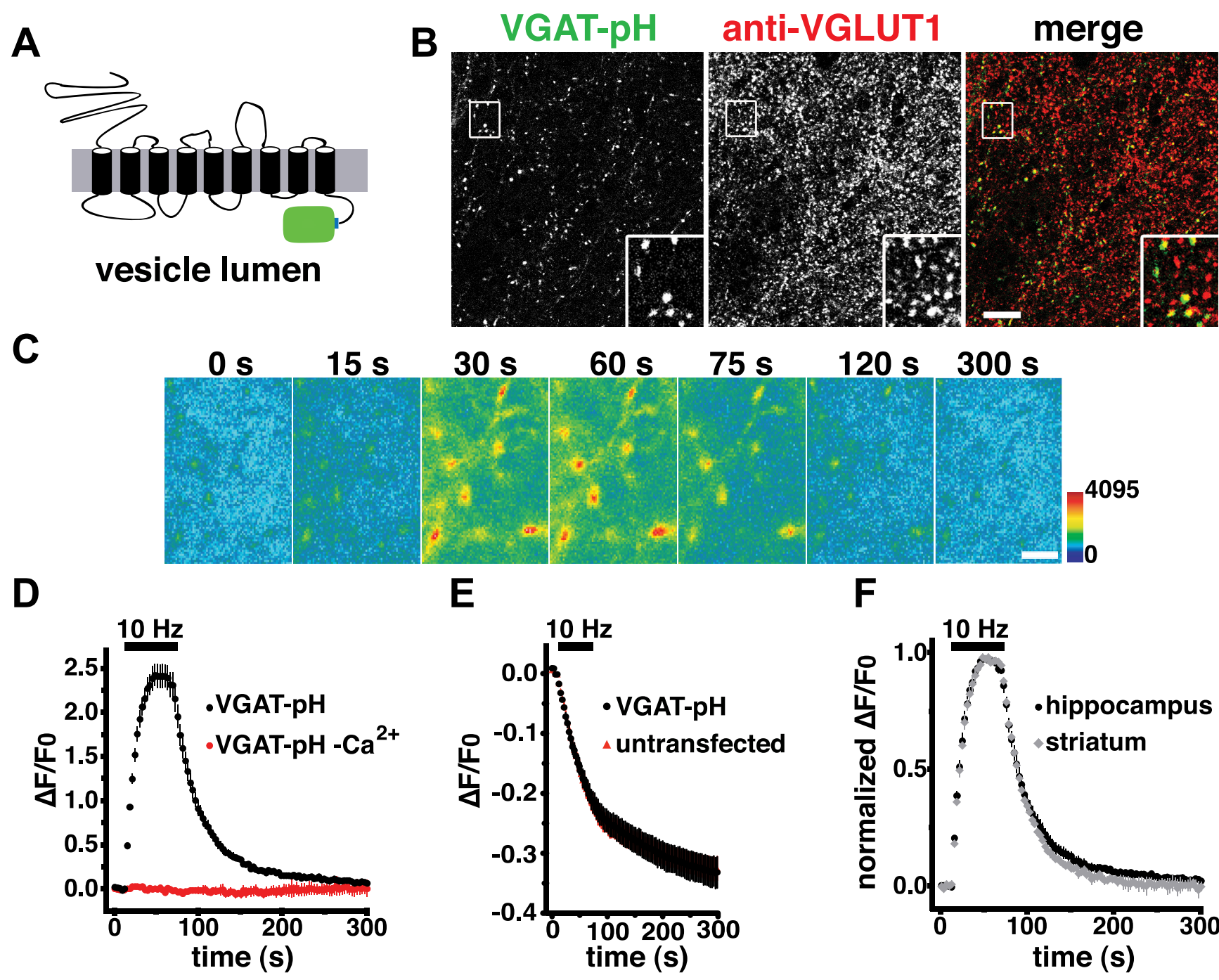

\section{$\mathbf{E}$}

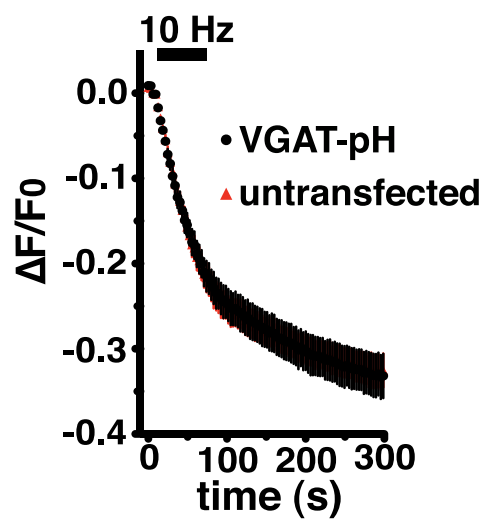

$\mathbf{F}$

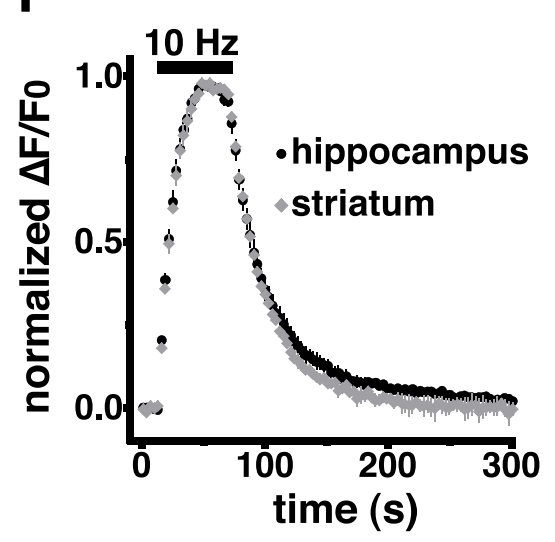

Figure 2. Development of a pHluorin-based reporter of VGAT vesicle recycling. $\boldsymbol{A}$, Schematic representation of VGAT-pH depicts pHluorin inserted at the lumenal C-terminus of rat VGAT. $\boldsymbol{B}$, VGAT-pH fluorescence colocalizes with VGLUT1 antibody staining at varicosities in transfected hippocampal neurons. Scale bar, $10 \mu \mathrm{m}$. $\boldsymbol{C}$, Time-lapse images show the fluorescence change of VGAT-pH in response to neural activity. After onset of a $10 \mathrm{~Hz} 60 \mathrm{~s}$ stimulus, exocytosis of VGAT-pH results in a rapid increase in fluorescence (15, 30 , and $60 \mathrm{~s}$ ), followed by fluorescence decay after the end of stimulation $(75,120$ and $300 \mathrm{~s}$ ) as the vesicles undergo endocytosis and reacidification. Color scale is shown to the right. Scale bar, $2 \mu \mathrm{m}$. D, Fluorescence intensity, normalized to baseline $\left(\Delta \mathrm{F} / \mathrm{F}_{0}\right)$, of VGAT-pH (black) increases during stimulation (bar) and decays with an exponential time course after termination of the stimulus $(\tau=33.03 \pm 1.79 \mathrm{~s})$, consistent with exocytosis followed by endocytosis. No change in fluorescence of VGAT-pH occurs in the absence of calcium (red). $\boldsymbol{E}$, There is no difference in the rate of FM4-64 destaining between boutons from untransfected (red) and transfected (black) neurons. $\boldsymbol{F}$, Kinetics of fluorescence changes are similar for VGAT-pH transfected in hippocampal (black, $\tau=33.03 \pm 1.79 \mathrm{~s}$ ) and striatal (gray, $\tau=30.55 \pm 2.98 \mathrm{~s}$ ) cultures. Data in $\boldsymbol{D}-\boldsymbol{F}$ are means \pm SEM of at least 20 boutons per coverslip (cs) from 6 to $9 \mathrm{cs}$ from at least three independent cultures.

hippocampal neurons (Fig. 3B, 0 s). FV/GG VGLUT1-pH fluorescence does increase in response to stimulation, indicating exocytosis (Fig. 3B, $60 \mathrm{~s}$ ). Importantly, WT VGAT-pH expressed in hippocampal or GABAergic neurons is targeted to SVs, whereas the FA/GG mutant is mistargeted (Fig. $3 B$ ). This suggests that protein identity, not SV membrane or neuronal cell type, controls sorting.

To explore the role of the acidic residues in the dileucine-like consensus sequence, we replaced $\mathrm{E}_{39} \mathrm{E}_{40}$ with glycine $\left(\mathrm{E}_{39} \mathrm{E}_{40} /\right.$ $\mathrm{GG})$. Although not grossly affecting VGAT-pH steady-state distribution, the EE/GG mutant exhibits a slowed rate of endocytosis after $10 \mathrm{~Hz} 60 \mathrm{~s}$ stimulation $(\tau=61.84 \pm 2.84 \mathrm{~s}$; Fig. $3 A)$. These results suggest that FA and EE cooperate to ensure efficient recycling of VGAT. We therefore asked whether mutating both the acidic and hydrophobic residues would have an even stronger effect on VGAT localization and trafficking. We used alanine replacement of $\mathrm{F}_{44}$, because the $\mathrm{F}_{44} \mathrm{~A} / \mathrm{AA}$ mutant is still localized to synapses, whereas glycine mutation abolishes synaptic targeting. Strikingly, the steady-state distribution of the combined mutant (4A) is similar to that of FA/GG (Fig. 3B,C). Namely, mutation of $\mathrm{E}_{39} \mathrm{E}_{40} \mathrm{~F}_{44}(4 \mathrm{~A})$ results in widespread expression of the transporter on the neuronal plasma membrane, with complete quenching of surface fluorescence at $\mathrm{pH} 5.5$ and no fluorescence increase upon application of $\mathrm{NH}_{4} \mathrm{Cl}$ (Fig. $3 \mathrm{C}$ ). Complete surface quenching indicates the mutant transporters are trapped on the plasma membrane with the C-terminal pHluorin facing the extracellular space. We also estimated the fraction of VGAT-pH stranded at the plasma membrane before and after stimulation. Transfected neurons were briefly exposed to an external $\mathrm{pH}$ of 5.5 before stimulation, and at the end of a four-min recovery period following $10 \mathrm{~Hz} 60 \mathrm{~s}$ stimulation. Surface fraction is estimated as the amount of fluorescence quenched by changing the $\mathrm{pH}$ from 7.4 to 5.5 , normalized to the total fluorescence measured upon application of $\mathrm{NH}_{4} \mathrm{Cl}$ to alkalinize SVs. WT 


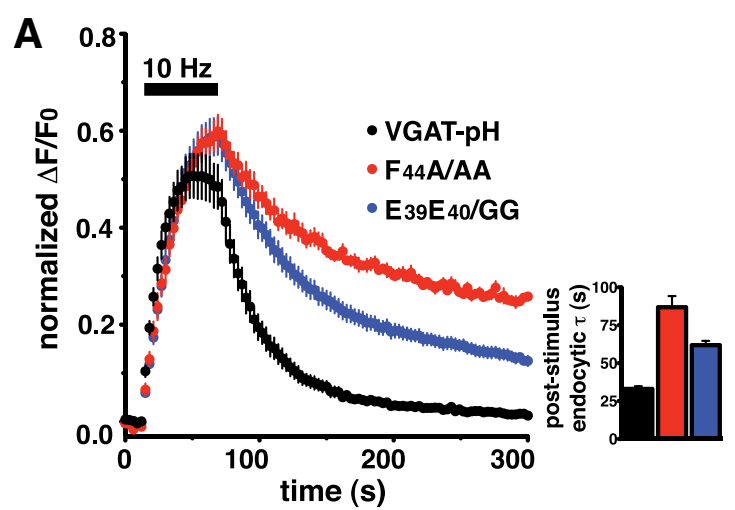

B
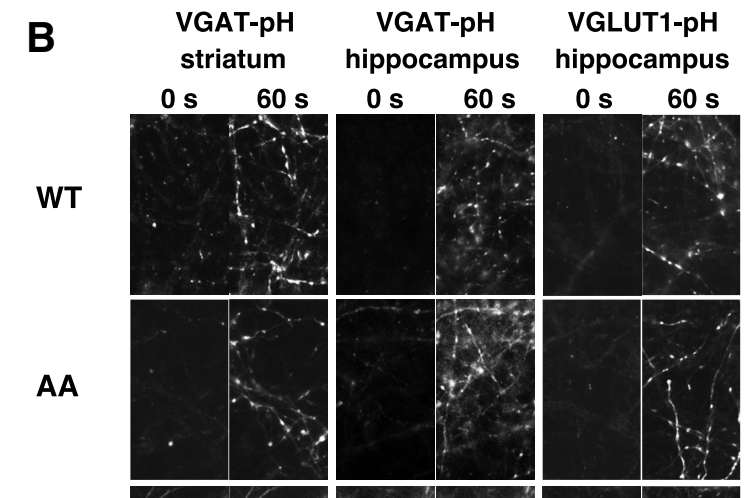

GG
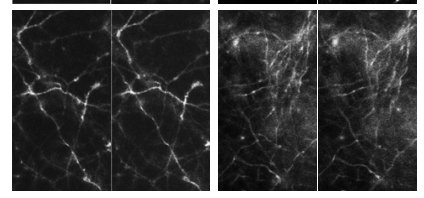

C

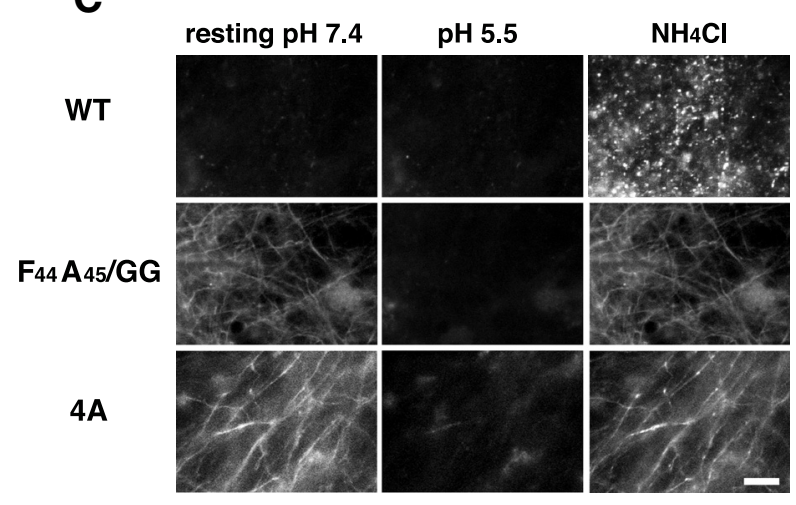

D

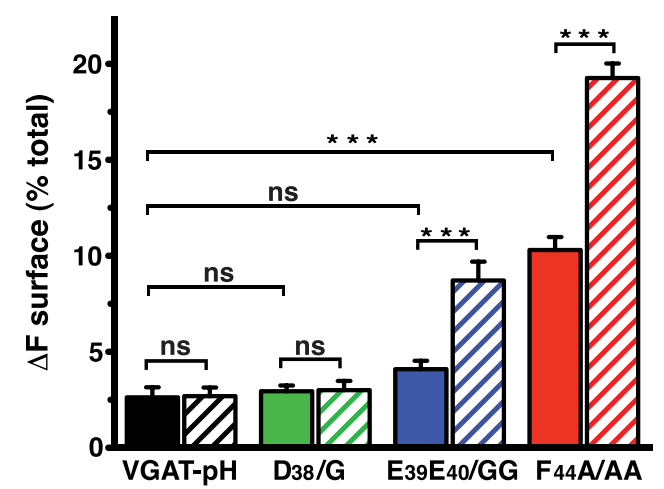

Figure 3. A single dileucine-like motif controls VGAT-pH synaptic targeting and recycling. $\boldsymbol{A}$, Mutation of $\mathrm{F}_{44}$ to alanine $\left(\mathrm{F}_{44} \mathrm{~A} / \mathrm{AA}\right.$, red) and of $\mathrm{E}_{39} \mathrm{E}_{40}$ to glycine $\left(\mathrm{E}_{39} \mathrm{E}_{40} / \mathrm{GG}\right.$, blue) slows VGAT-pH endocytosis after stimulation (WT: black, $\tau=33.03 \pm 1.79 \mathrm{~s}$, FA/AA: $\tau=86.88 \pm$
VGAT-pH exhibits a low steady-state level of surface expression $(2.6 \pm 0.5 \%)$ (Fig. 3D), similar to that measured for VGLUT1-pH (2.0 $\pm 0.8 \%)$ (Balaji and Ryan, 2007). The surface fraction of WT VGAT-pH returns to baseline levels after poststimulus endocytosis $(2.7 \pm 0.4 \%)$ (Fig. $3 D)$. In contrast, surface expression of the $\mathrm{E}_{39} \mathrm{E}_{40} / \mathrm{GG}$ mutant is relatively low under resting conditions $(4.1 \pm 0.4 \%)$, but does not return to baseline after stimulation $(8.7 \pm 0.9 \%)$, suggesting a less efficient endocytic process. Surface expression of $\mathrm{F}_{44} \mathrm{~A}_{45} / \mathrm{AA}$ is higher under resting conditions $(10.3 \pm 0.7 \%)$, and after stimulation $(19.3 \pm 0.8 \%)$ (Fig. $3 D$ ). The data presented here indicate the motif $\mathrm{E}_{39} \mathrm{EAVGFA}_{45}$ is the major sorting signal for trafficking of VGAT to SVs, and is therefore essential for GABAergic neurotransmission.

\section{VGAT interacts with clathrin adaptor proteins through its} dileucine-like motif

To investigate the biochemical interaction of the dileucine-like motif with endocytic adaptor complexes, we performed GST pull-down experiments. WT and mutant GST-VGAT N-terminal fusions bound to glutathione beads were incubated with rat brain homogenate, and analyzed by immunoblotting with antibodies to AP-1, AP-2, and AP-3 complexes. GST-VGAT specifically pulls down AP-2, which is known to be important for SV recycling. Mutation of either the hydrophobic (FA) or acidic (EE) residues greatly reduces this interaction (Fig. $4 A$, left), consistent with the slow rates of endocytosis observed in live cell imaging (Fig. 3A). Very little specific binding to AP-1 is observed and is not affected by any VGAT mutations tested (Fig. $4 A$, right).

Immediately upstream of the acidic dileucine-like motif in VGAT is another acidic residue, $\mathrm{D}_{38}$. Although outside the canonical motif, several other SV proteins also contain a charged residue in this position. The SV targeting motif of synaptotagmin contains a dileucine-like motif preceded by an acidic residue (Blagoveshchenskaya et al., 1999). On the other hand, VMAT2 and VAChT have positively charged residues, lysine and arginine, respectively (Erickson et al., 1994; Tan et al., 1998). All VGLUTs have a serine that, if phosphorylated, would become negatively charged (Voglmaier et al., 2006). Remarkably, mutation of $\mathrm{D}_{38}$ to glycine significantly increases the interaction of VGAT with AP-3 (Fig. 4A, middle). Dileucine-like motifs have been shown to be crucial for the interaction of AP-3 with several cargo proteins

$\leftarrow$

$7.37 \mathrm{~s}$, EE/GG: $\tau=61.84 \pm 2.84$ s). $\boldsymbol{B}$, Left and middle, The fluorescence of both WT VGAT-pH and the FA/AA mutant expressed in striatal and hippocampal neurons is largely quenched before stimulation ( $0 \mathrm{~s}$ ). Mutation of $\mathrm{F}_{44} \mathrm{~A}_{45}$ to $\mathrm{GG}$ results in an altered distribution throughout the processes (GG). Upon stimulation (60 S), WT and AA exhibit fluorescence increases consistent with exocytosis, but maintain a punctate localization. Mutation of FA to GG abolishes synaptic targeting and response to stimulation. Right, the analogous mutations in VGLUT1-pH in hippocampal neurons show that VGAT-pH and VGLUT1-pH GG mutants display differences in cell surface localization $(\mathrm{GG}, 0 \mathrm{~s})$ and response to stimulation $(\mathrm{GG}, 0 \mathrm{vs} 60 \mathrm{~s})$. C, Fluorescence of WT VGAT-pH is quenched at resting conditions, and thus not sensitive to acid quenching by $\mathrm{pH}$ 5.5 Tyrode's solution added to the outside of cells (top). Mutation of residues $\mathrm{E}_{39}, \mathrm{E}_{40}$ and $\mathrm{F}_{44}$ renders VGAT-pH sensitive to acid quenching ( $4 A$, bottom), similar to FA/GG (middle). $\boldsymbol{D}$, The surface fraction of WT VGAT-pH and D/G and EE/GG mutants are not significantly different before stimulation (WT, $2.6 \pm 0.5 \% ; \mathrm{D} / \mathrm{G}, 2.9 \pm 0.3 \%$; $\mathrm{EE} / \mathrm{GG}, 4.1 \pm 0.4 \%$ ). However, the surface fraction of $\mathrm{EE} / \mathrm{GG}$ is significantly higher after stimulation (WT, $2.7 \pm 0.4 \%$; $\mathrm{D} / \mathrm{G}$, $3.0 \pm 0.5 \%$; EE/GG, $8.7 \pm 1.0 \%$ ). FA/AA exhibits higher cell-surface expression both before $(10.3 \pm 0.7 \%)$ and after $(19.3 \pm 0.8 \%)$ stimulation. Solid and hatched bars represent fraction of surface fluorescence at steady-state and after endocytosis is allowed to proceed for 4 min after stimulation, respectively. Results are mean $\pm \mathrm{SEM}$ of $\Delta \mathrm{F} / \mathrm{F}_{0}$ normalized to total fluorescence $\left(\mathrm{NH}_{4} \mathrm{Cl}\right)$ of at least 20 boutons per cs from 8 to $15 \mathrm{cs}$ from 3 to 5 independent cultures. ${ }^{* *} p<0.001$, one-way ANOVA. 
A
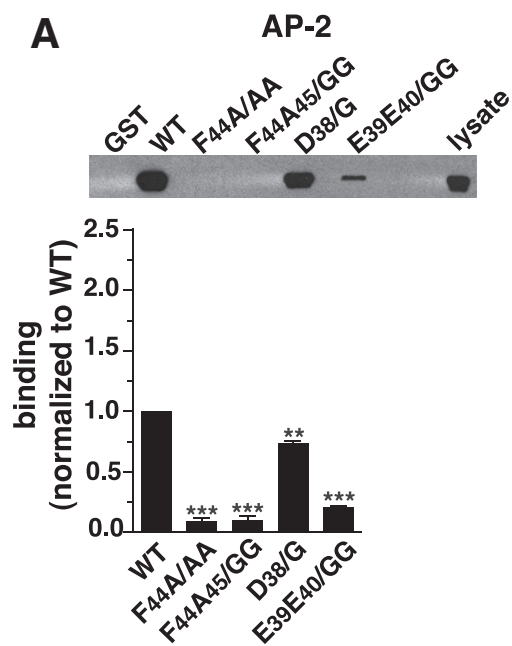

C

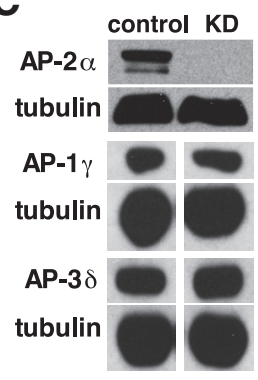

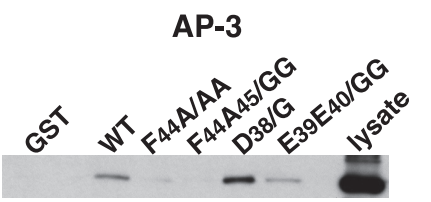

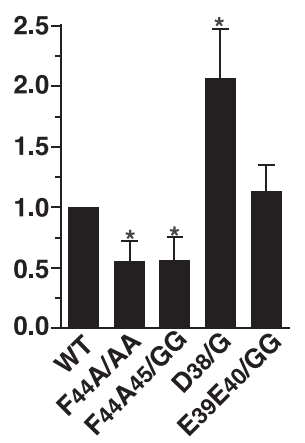

AP-1
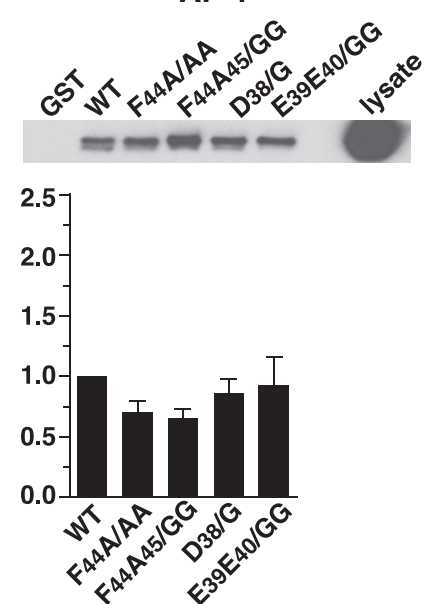

B
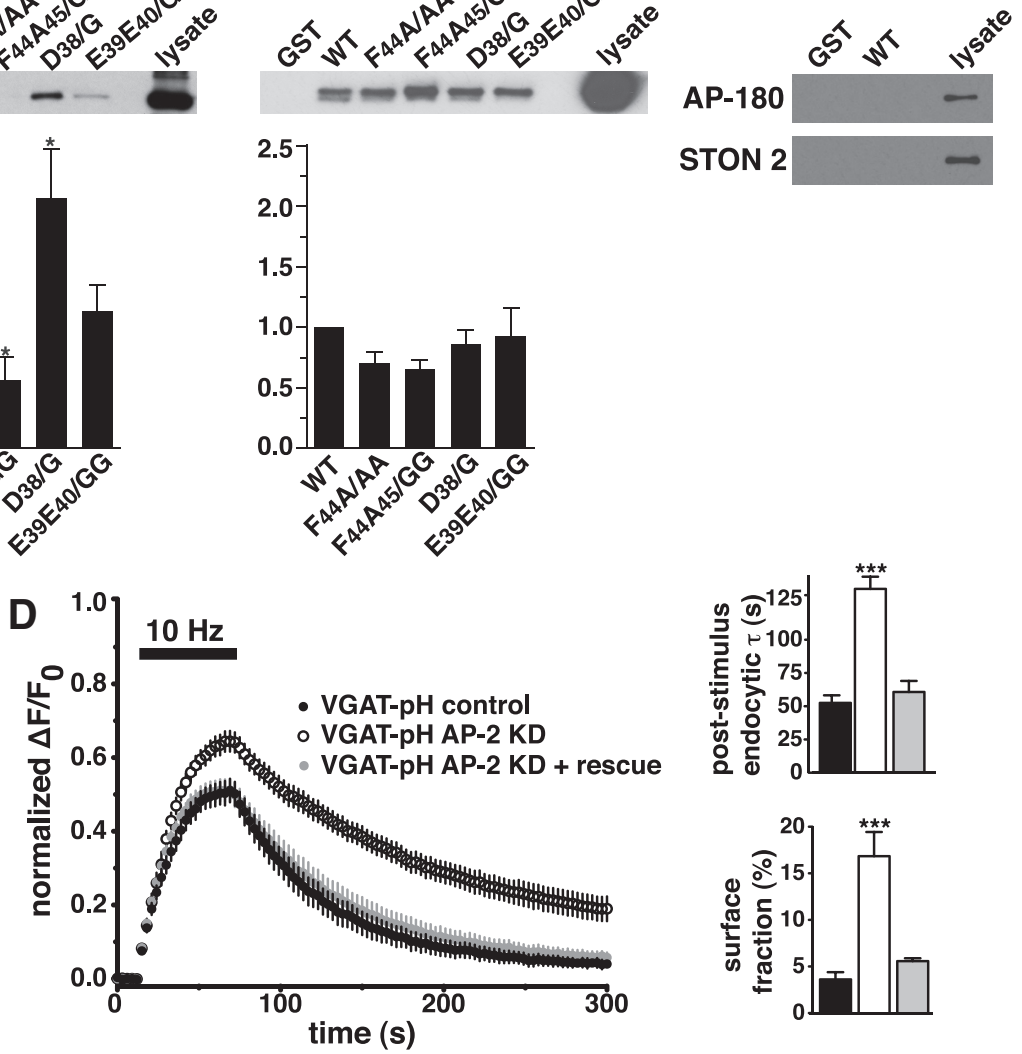

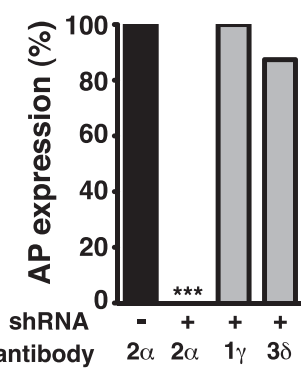

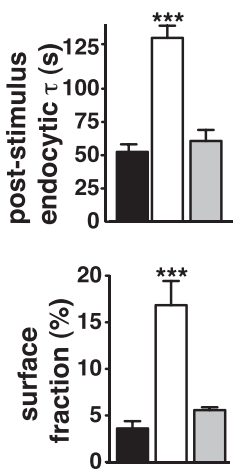

Figure 4. VGAT interacts with clathrin adaptor proteins through its dileucine-like motif. A, A GST fusion of the WT VGAT N-terminus pulls down AP-2 from rat brain lysates, but mutation of the dileucine-like motif disrupts the interaction. The D/G mutant interacts more strongly with AP-3, whereas none of the mutations tested affects interaction of VGAT with AP-1. Bound proteins were detected by immunoblotting with antibodies against AP-1 (anti-adaptin $\gamma$ ), AP-2 (anti-adaptin $\alpha$ ), and AP-3 (anti- $\beta$-NAP). Top panels show representative immunoblots, bottom show the averaged quantification of band intensity from at least three independent experiments. ${ }^{*} p<0.05,{ }^{* *} p<0.001,{ }^{* * *} p<0.0001$, one-way ANOVA. B, No binding to AP180 or stonin 2 is detected with the same pull down experiments described in A and immunoblotting with antibodies against AP180 and stonin 2.C, AP-2 protein, but not AP-10r AP-3, is specifically depleted by lentiviral expression of AP- $2 \mu 2$ shRNA, as shown by immunoblot analysis of hippocampal neuron extracts (left). Right, quantified band intensity, averaged from 2 independent experiments, ${ }^{* * *} p<0.0001$, one-way ANOVA. $D$, Depletion of AP-2 slows endocytosis of VGAT-pH after stimulation, whereas expression of the shRNA-resistant $\mu 2$ rescues this effect (control $\tau=52.46 \pm 5.65 \mathrm{~s}$, AP-2KD $\tau=$ $129.73 \pm 9.21 \mathrm{~s}$, rescue $\tau=60.71 \pm 8.36 \mathrm{~s}$ ). Data are means $\pm \mathrm{SEM}$ of $\Delta \mathrm{F} / \mathrm{F}_{0}$ normalized to total fluorescence from at least 30 boutons per cs from $7 \mathrm{to} 14 \mathrm{cs}$ from at least two independent cultures. Bottom, In neurons depleted of AP-2, a larger fraction of VGAT-pH remains on the cell surface after stimulation and recovery, which is reversed by expression of the shRNA-resistant $\mu 2$ (control $3.6 \pm$ $0.8 \%$, AP2-KD $16.8 \pm 2.6 \%$, rescue $5.6 \pm 0.3 \%),{ }^{* * *} p<0.001$, one-way ANOVA.

including tyrosinase, LIMPII, and PI4KII $\alpha$ (Honing et al., 1998; Rodionov et al., 2002; Theos et al., 2005; Craige et al., 2008). Some work has suggested a proline residue in the -1 position and a positively charged residue in the -3 position of the acidic dileucine motif may be important in specifying AP-3 binding in LIMPII (Rodionov et al., 2002); however, there is no known consensus that unambiguously predicts which AP isoform will interact with cargo proteins.

There has been compelling evidence for the involvement of proteins other than the clathrin APs in endocytosis of SV proteins. For example, internalization and recycling of synaptotagmin requires interaction with stonin 2 , which directly interacts with AP-2 (Diril et al., 2006; Jung et al., 2007). The Drosophila stonin homolog may also affect VGLUT localization (Mohrmann et al., 2008). In Caenorhabditis elegans unc-41/stonin mutants, synaptotagmin localization is severely impaired but only modest mislocalization of other SV proteins, including synaptobrevin, synaptogyrin, VAChT, and VGAT, is observed (Mullen et al., 2012) (but see Willox and Royle, 2012). Endocytosis of the $\mathrm{v}$-SNARE synaptobrevin requires specific interaction of the SNARE motif in the $\mathrm{N}$-terminus with the adaptor proteins AP180 and CALM (Koo et al., 2011). We tested whether the N-terminus of VGAT interacts with these alternate adaptors in GST pulldowns, immunoblotting with antibodies to stonin 2 and AP180. No binding of VGAT to stonin 2 or AP180 was detected (Fig. $4 B$ ). Although we cannot rule out a low affinity cargo-adaptor interaction (Rapoport et al., 1998), the GST-VGAT N-terminus does bind clathrin APs under the same conditions.

To determine whether the in vitro binding to AP-2 has corresponding functional relevance to VGAT recycling at the nerve terminal, we performed shRNA-mediated knockdown of AP-2 and measured VGAT-pH recycling kinetics in response to 600 action potentials at $10 \mathrm{~Hz}$. Neurons were infected with lentivirus containing an shRNA oligonucleotide to rat AP-2 $\mu 2$ (Kim and Ryan, 2009) at DIV 7 to avoid developmental effects of AP-2 depletion. The shRNA for $\mu 2$ used here specifically depletes AP-2, with no significant effect on expression of AP-1 and AP-3 (Fig. 4C). Depletion of AP-2 severely slows VGAT-pH endocytosis after stimulation, corroborating the results observed with GST pull-down experiments (control $\tau=52.46 \pm 5.65 \mathrm{~s}, \mathrm{AP}-2 \mathrm{KD} \tau=$ $129.73 \pm 9.21$ s, Fig. 4D). Moreover, coexpression of an shRNAresistant $\mu 2$ (Kim and Ryan, 2009) rescues this impairment, further confirming that the phenotype is specifically due to loss of AP-2 (rescue $\tau=60.71 \pm 8.36$ s; Fig. $4 D$ ). Increased surface 

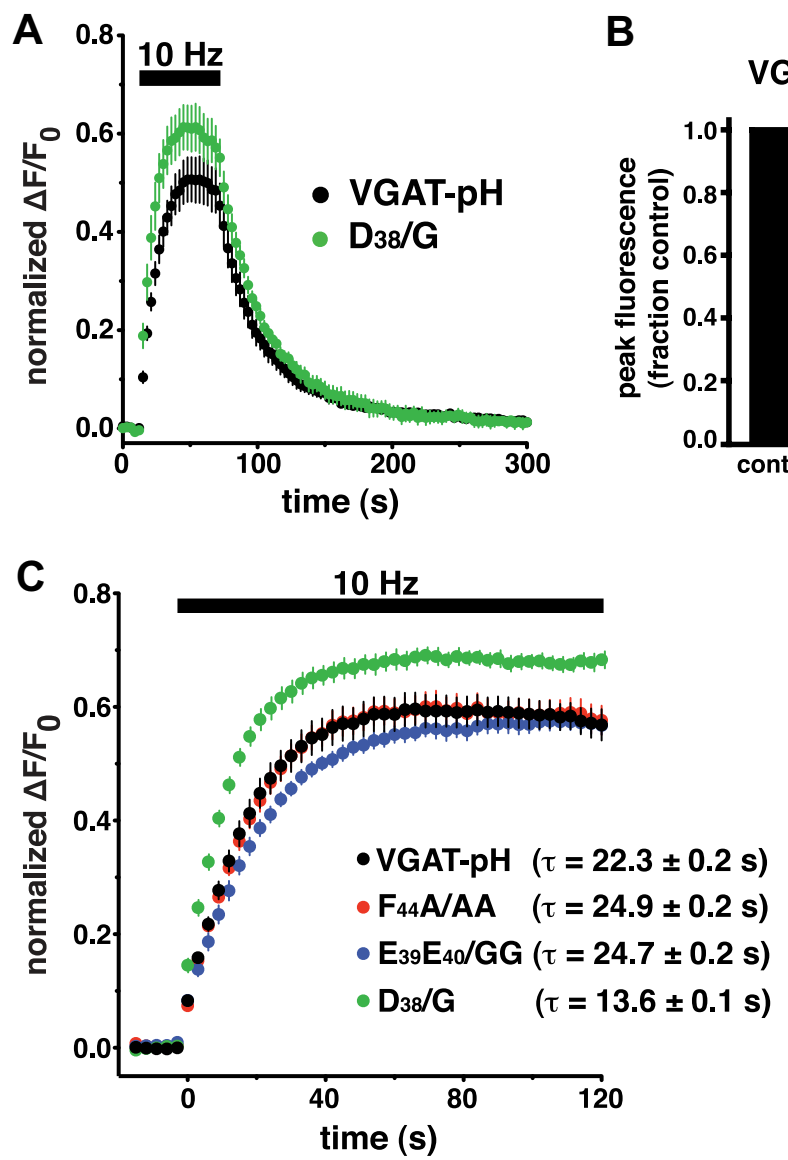
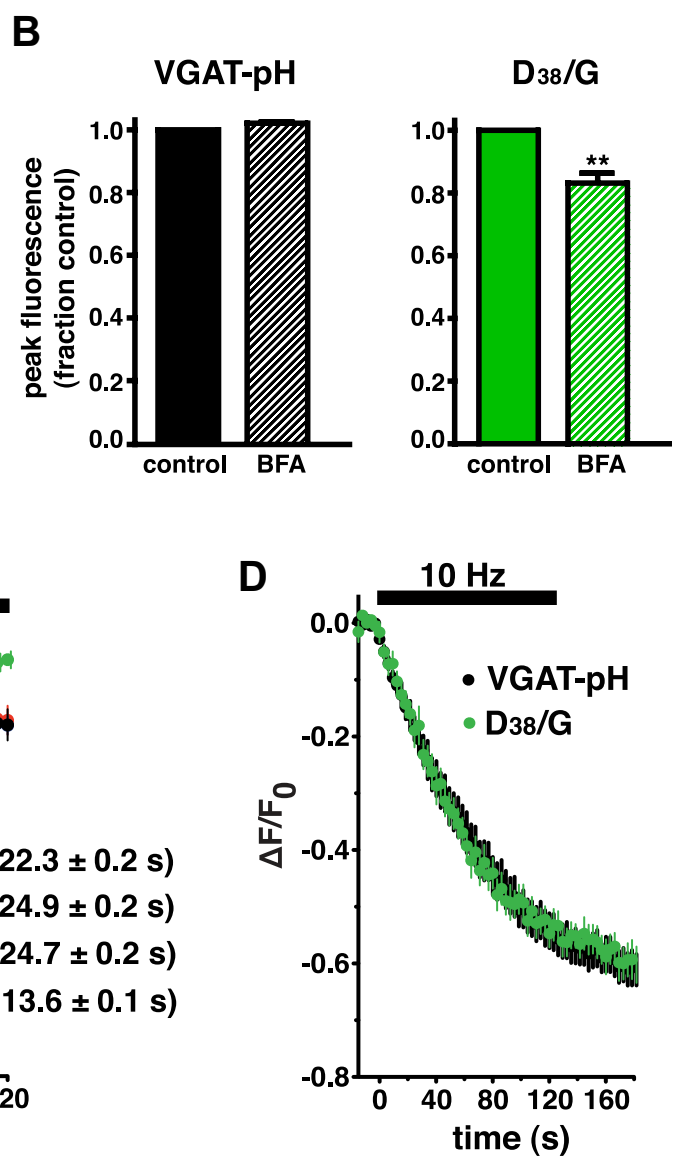

Figure 5. Mutation of $\mathrm{D}_{38}$ to $\mathrm{G}$ alters $\mathrm{VGAT}$ recycling kinetics during stimulation. $A$, Upon stimulation, fluorescence of $\mathrm{D} / \mathrm{G} \mathrm{VGAT-pH}$ (green, $\Delta \mathrm{F} / \mathrm{F}_{0}$ normalized to total fluorescence) rises faster and peaks higher than WT (black) (WT peak: $0.5050 \pm 0.0012, \mathrm{D} / \mathrm{G}$ peak: $0.6123 \pm 0.0007, p<0.0001$ by two-tailed, unpaired $t$ test). $B$, BFA has no effect on the recycling of WT VGAT-pH (hatched black bar), but reduces the peak fluorescence of D/G VGAT-pH (hatched green bar), ${ }^{* *} p=0.0012$ by two-tailed, unpaired $t$ test. C, D/G VGAT-pH (green) exhibits a faster initial rate of exocytosis $(\tau=$ $13.6 \pm 0.1 \mathrm{~s}$ ) compared with WT VGAT-pH (black, $\tau=22.3 \pm 0.2 \mathrm{~s}$ ). The proportion of $\mathrm{D} / \mathrm{G}$ that undergoes exocytosis $(0.688 \pm 0.003)$ is also significantly increased compared with WT ( $0.593 \pm$ 0.001). Neither FA/AA (red) nor EE/GG (blue) mutation significantly alters the rate of VGAT-pH exocytosis (FA/AA, $\tau=24.9 \pm 0.2 \mathrm{~s}$; EE/GG, $\tau=24.7 \pm 0.3 \mathrm{~s}$ ) or the size of the recycling pool. $\boldsymbol{D}$, The rate of FM5-95 destaining is not significantly different between boutons transfected with WT and D/G VGAT-pH. Data are means $\pm S E M$ of $\Delta F / F_{0}$ normalized to total fluorescence from at least 20 boutons per cs from 6 to $17 \mathrm{cs}$ from at least three independent cultures.

expression of VGAT-pH is observed in AP-2 KD neurons after stimulation (Fig. 4D), similar to the results observed for dileucine-like motif mutants (Fig. $3 A, D$ ). This effect is reversed with expression of the shRNA-resistant $\mu 2$ (Fig. 4D).

Selective modulation of VGAT recycling during stimulation by a single-point mutation

To determine whether the increased in vitro binding of the $\mathrm{D} / \mathrm{G}$ VGAT mutant to AP-3 has a functional correlate, we examined the distribution and recycling of D/G VGAT-pH in neurons. A role for the alternate adaptors, AP-1 and AP-3, in SV formation, recycling, and distribution has been demonstrated in several studies (Faundez et al., 1998; Scheuber et al., 2006; Voglmaier et al., 2006; Glyvuk et al., 2010; Cheung and Cousin, 2012). Mutation of $\mathrm{D}_{38}$ to $\mathrm{G}$ does not affect the steady-state distribution (Fig. $3 D$ ) or retrieval of VGAT-pH from the cell surface after $10 \mathrm{~Hz} 60 \mathrm{~s}$ stimulation $(\tau=34.8 \pm 2.2 \mathrm{~s}$; Fig. $5 A$ ). However, during stimulation, the fluorescence intensity of D/G VGAT-pH rises faster and reaches a higher peak than WT, reflecting a difference in the balance of exo- and endocytosis (Fig. 5A). We measured VGAT-pH recycling in the presence of BFA, as described previously (Voglmaier et al., 2006). BFA inhibits AP-1 and AP-3 pathways as a consequence of its inhibition of the activity of the ADP ribosylation factor 1 GTP exchange factor (ARF-GEF), which influences the cycling of AP-1 and AP-3 to membranes. (Donaldson et al., 1992; Helms and Rothman, 1992). Consistent with the weaker AP-3 binding observed in vitro, incubation of neurons with BFA does not alter recycling of WT VGAT-pH under these conditions (Fig. 5B). In contrast, BFA reduces the peak surface level of D/G VGAT-pH (Fig. 5B). Several studies have suggested that recycling occurring during stimulation is mediated by different molecular mechanisms than after stimulation (Voglmaier et al., 2006; Ferguson et al., 2007; Mani et al., 2007; Kwon and Chapman, 2011) (but see Balaji et al., 2008). Interestingly, BFA did not affect the poststimulus rate of endocytosis in either the WT or $\mathrm{D}_{38} / \mathrm{G}$ mutant (WT: control $\tau=34.1 \pm 2.9 \mathrm{~s}$, BFA $\tau=$ $33.8 \pm 1.9 \mathrm{~s} ; \mathrm{D}_{38} / \mathrm{G}$ : control $\tau=32.9 \pm 3.8 \mathrm{~s}$; BFA $\tau=30.4 \pm$ $2.7 \mathrm{~s})$. The effect of BFA is thus specific for the period during stimulation.

To determine whether the higher peak level of fluorescence during stimulation that is observed for D/G VGAT-pH compared with WT corresponds to an increased recycling pool, we used alkaline trapping with the $\mathrm{H}^{+}$-ATPase inhibitor bafilomycin to prevent reacidification of the vesicles that have undergone exocytosis (Sankaranarayanan and Ryan, 2001). Neurons were stimulated in the presence of bafilomycin with 1200 action potentials at $10 \mathrm{~Hz}$ to release the entire recycling pool (Ariel and Ryan, 2010). The initial exponential rate of exocytosis of the $D / G$ 
VGAT-pH mutant $(\tau=13.6 \pm 0.1 \mathrm{~s})$ is significantly faster than $\mathrm{WT}(\tau=22.3 \pm 0.2 \mathrm{~s})$. The exocytosis rates of FA/AA $(\tau=24.9 \pm$ $0.2 \mathrm{~s})$ and EE/GG $(\tau=24.7 \pm 0.3 \mathrm{~s})$ are not significantly different from WT. Additionally, the proportion of D/G VGAT-pH that undergoes exocytosis upon stimulation is $\sim 17 \%$ larger than $\mathrm{WT}$, FA/AA, or EE/GG VGAT-pH (Fig. 3C). To determine whether the increase in exocytosis is due to an increase in the release of SVs from the recycling pool or to a change in the distribution of the transporter between different synaptic vesicle pools, we measured FM5-95 styryl dye unloading in response to $10 \mathrm{~Hz} 120 \mathrm{~s}$ stimulation (Fig. 5D). There are no significant differences in the rate or extent of FM release between WT and D/G VGAT, suggesting that the proteins differentially sort to the recycling pool.

\section{Increased D/G VGAT-pH in the RRP is dependent on AP-3}

Because the largest differences in recycling were observed during the initial phase of stimulation, we wondered whether a larger proportion of D/G VGAT-pH resides in the RRP. We therefore measured the amount of fluorescence increase upon release of vesicles from the RRP, using a defined stimulus of 20 action potentials at $100 \mathrm{~Hz}$ (Ariel and Ryan, 2010). Indeed, the fraction of $\mathrm{D} / \mathrm{G}$ VGAT-pH protein released by this stimulus $(7.14 \pm 0.04 \%)$ is $\sim 50 \%$ larger than WT VGAT-pH $(4.69 \pm 0.05 \%$ ) (Fig. $6 A$ ). A similar increase of D/G VGAT-pH in the RRP is observed when neurons are challenged with hypertonic sucrose, an independent approach to measure the RRP (Rosenmund and Stevens, 1996; Nemani et al., 2010) (Fig. 6B).

To determine whether AP-3 is necessary for the increase in $\mathrm{D} / \mathrm{G}$ VGAT-pH in the RRP, we depleted this adaptor protein from neurons using an shRNA oligonucleotide to rat AP- $3 \delta 1$ based on an siRNA sequence that specifically abolishes expression of AP-3 with no off-target effects (Asensio et al., 2010). Immunoblot analysis of extracts from hippocampal neurons infected with lentivirus expressing AP- $3 \delta 1$ shRNA shows a substantial reduction in expression level of AP- $3 \delta$ without any decrease of AP-1 $\gamma$ or AP- $2 \alpha$ (Fig. $6 C$ ). Neurons expressing WT or D/G VGAT-pH were infected with either a control or shRNA vector and stimulated with 20 action potentials at $100 \mathrm{~Hz}$ to release the RRP. The amount of WT VGAT-pH released in the RRP is insensitive to knockdown of AP-3 (Fig. 6D). In contrast, the proportion of D/G VGAT-pH in the RRP reverts to WT levels upon depletion of AP-3 (Fig. 6D).

A question that arises from these observations is whether AP-3 is acting locally at the terminal, or whether its actions are mainly in the biosynthetic pathway (Asensio et al., 2010) or endosomal pools (Larimore et al., 2011) located in the cell bodies. To address this question, we used BFA to acutely inhibit the AP-3 pathway. If AP-3 plays a role locally, acute treatment should mimic the results of AP-3 knockdown experiments. If, on the other hand, it is biosynthesis in the soma and delivery to the bouton that are dependent on AP-3, short-term inhibition should not affect the RRP. We therefore performed the same experiments in neurons treated with BFA for $30 \mathrm{~min}$. The results in Figure $6 E$ show that indeed BFA reduces the D/G RRP to WT levels, as observed in AP-3 knockdown experiments. Because BFA could also inhibit the AP-1-dependent pathway, we tested whether this drug has any additional effect on the amount of D/G VGAT-pH released from terminals depleted of AP-3 by knockdown. Combination of BFA with AP-3 knockdown does not result in any additional effect on the amount of D/G VGAT-pH in the RRP using either 20 action potentials at $100 \mathrm{~Hz}$ (Fig. $6 F$ ) or an alternate stimulus of 90 action potentials at $30 \mathrm{~Hz}$ (Fig. 6G) (Pyle et al., 2000). Therefore, inhibition of the AP-1 pathway does not affect the amount of D/G VGAT in the RRP. Furthermore, expression of shRNA resistant AP-3 $\delta 1$ rescues the decrease observed with AP-3 knockdown, confirming that the phenotype is specifically due to depletion of AP-3 (Fig. 6G). Thus, the increased RRP size observed for $\mathrm{D} / \mathrm{G}$ VGAT-pH is dependent upon its interaction with AP-3 at the presynaptic bouton.

\section{Discussion}

In this work, we show that a single unconventional dileucine-like motif is essential for synaptic localization and recycling of VGAT. Variations of the consensus sequence (D/E)XXXL(L/I) have been reported (Bonifacino and Traub, 2003). Interestingly, the $\mathrm{N}$-terminal VGAT sequence contains alanine as one of the hydrophobic residues in the endogenous dileucine-like sequence. This observation reveals a greater diversity among dileucine-based sorting signals than previously recognized, and suggests that there may be more variations yet to be described. The replacement of $\mathrm{F}_{44}$ with alanine (FA/AA) is enough to significantly impair internalization of VGAT, though the protein still targets to SVs. To assess the contribution of $\mathrm{A}_{45}$, we used glycine substitution. Glycine replacement has occasionally been used in the analysis of membrane protein trafficking (Honing et al., 1998), but the majority of studies use alanine, sometimes with only partial impairment (Bonifacino and Traub, 2003). Our results suggest that by more thoroughly blocking AP interactions, glycine substitution is a more effective strategy to analyze dileucine motifmediated protein trafficking. In VGAT, mutation of FA to glycine results in a drastic change in VGAT subcellular localization, underscoring the importance of $\mathrm{F}_{44} \mathrm{~A}_{45}$ to synaptic targeting of VGAT. Two pieces of evidence support the notion that protein identity, rather than neuronal cell type or SV membrane, controls the sorting of synaptic proteins: (1) the VGAT mutant has the same expression profile whether expressed in hippocampal or striatal neurons, and (2) in stark contrast to FA/GG VGAT, VGLUT1 containing the analogous mutation (FV/GG) has a profile more similar to WT VGLUT1.

The acidic residues $\mathrm{E}_{39} \mathrm{E}_{40}$ are also important for endocytosis of VGAT. The contribution of acidic residues to dileucine motifmediated trafficking differs for individual proteins. For example, an acidic residue in LIMPII is important for targeting to lysosomes, but not for internalization, whereas the -4 and -5 acidic residues are required for internalization of chimeric CD4/CD3 $\gamma$ receptors (Pond et al., 1995; Sandoval et al., 2000). Mutation of acidic residues in the dileucine-like motif of VMAT2 disrupts targeting to the somatodendritic secretory pathway, but endocytosis in cell bodies is not affected (Tan et al., 1998; Li et al., 2005; Asensio et al., 2010). This study is the first investigation of acidic residues in SV protein recycling at the nerve terminal and reveals their important role in VGAT endocytosis. The presence of alanine in the dileucine-like motif could result in a relatively weak interaction between the hydrophobic residues and APs. In this case, the acidic residues of VGAT may significantly contribute to the robustness of AP binding (Bonifacino and Traub, 2003). The impairment of synaptic targeting observed for the VGAT mutant $4 \mathrm{~A}$, in which $\mathrm{E}_{39}, \mathrm{E}_{40}$ and $\mathrm{F}_{44}$ are replaced with alanine reinforces the notion that FA and EE cooperate to effect efficient recycling of VGAT. Interestingly, excitotoxic insult triggers cleavage of a part of the VGAT N-terminus that encompasses the dileucine-like motif, resulting in a distribution of VGAT similar to the FA/GG and $4 \mathrm{~A}$ mutants (Gomes et al., 2011)

These observations led us to investigate the mechanism(s) by which the endocytic motif of VGAT acts. Localization and endocytosis of many SV proteins depend upon the interaction of spe- 
A

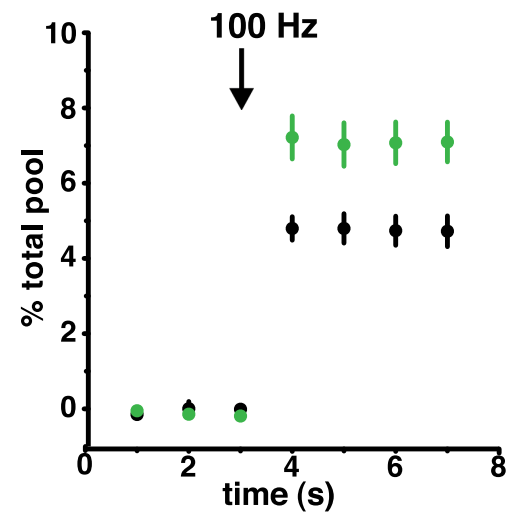

C

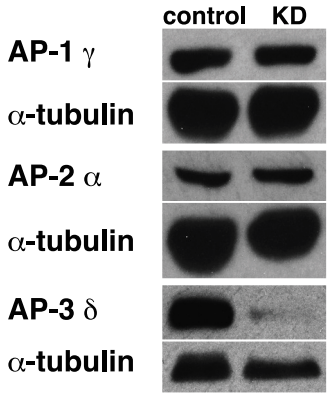

B

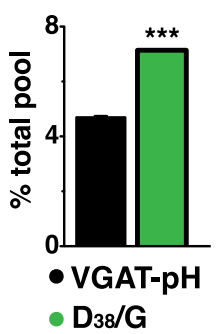

sucrose

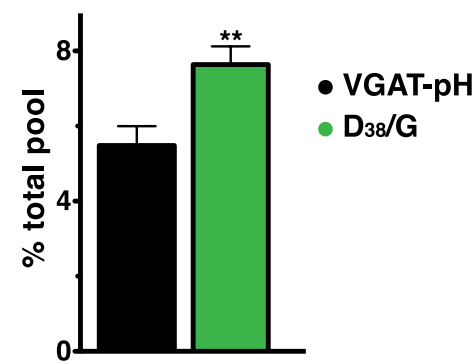

D

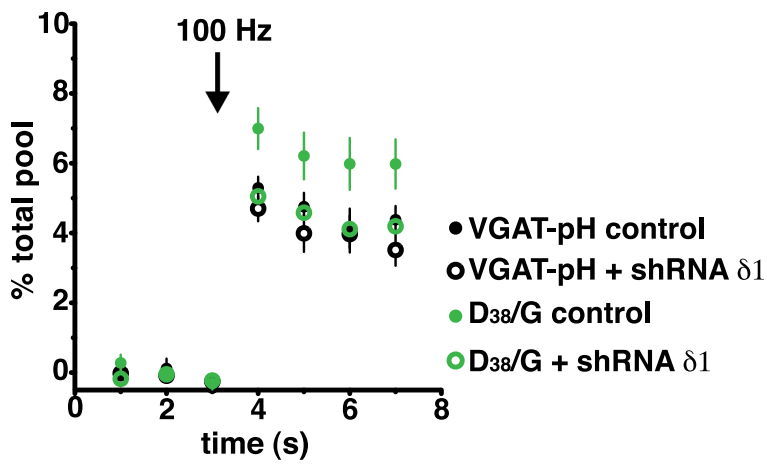

$\mathbf{F}$

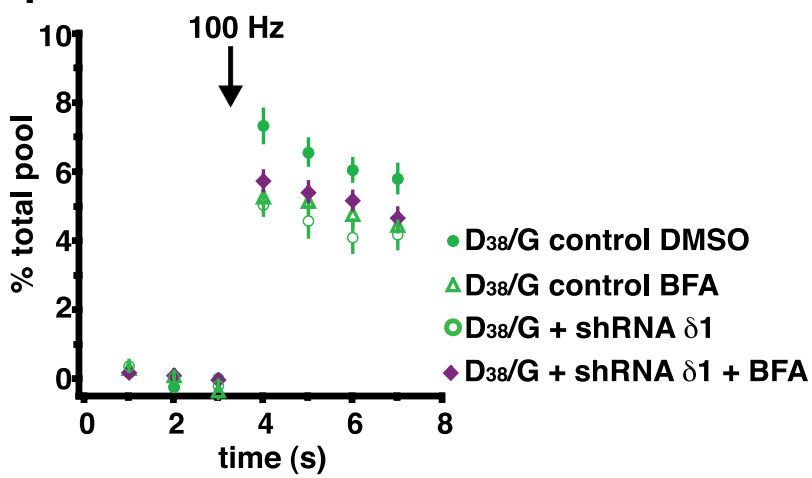

E

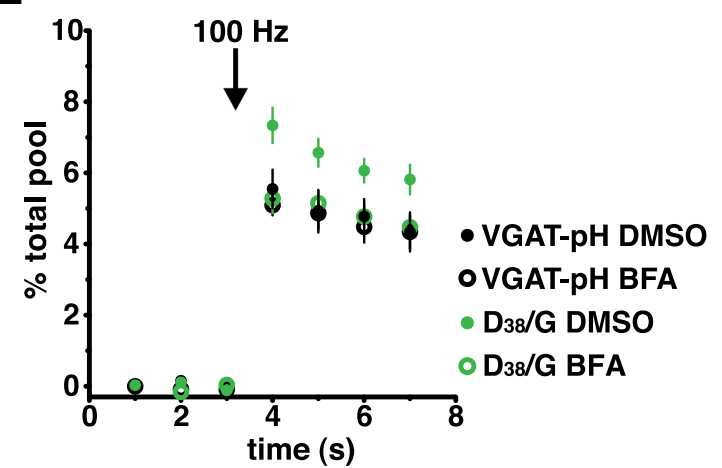

G

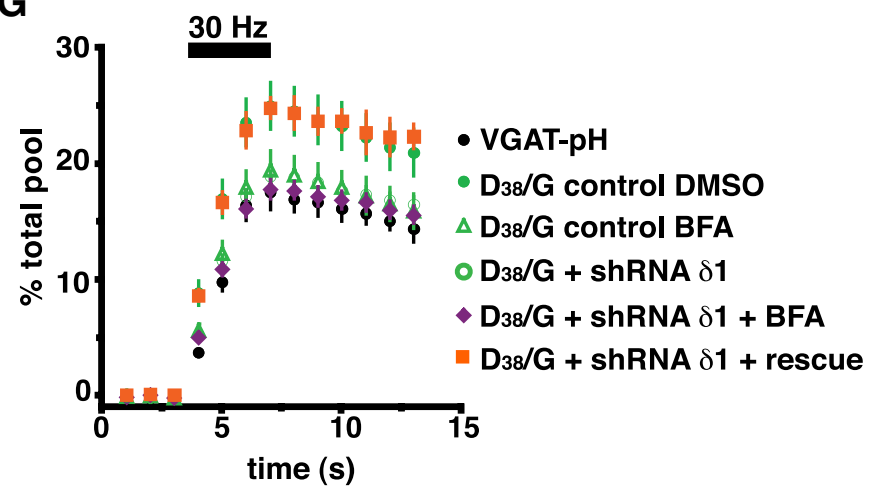

Figure 6. Increased D/G VGAT-pH in the RRP is mediated by AP-3.A, Exocytosis from the RRP is evoked using a stimulus of 20 action potentials at $100 \mathrm{~Hz}$. Inset: the fraction of D/G VGAT-pH (green) released by RRP stimulation $(7.14 \pm 0.04 \%)$ is $\sim 50 \%$ larger than WT VGAT-pH ( $4.69 \pm 0.05 \%$, black), ${ }^{* * *} p<0.0001$ by two-tailed, unpaired $t$ test. $\boldsymbol{B}$, Exocytosis from the RRP is evoked by application of Tyrode's solution containing $300 \mathrm{~mm}$ sucrose in the presence of $1 \mu \mathrm{m}$ bafilomycin to prevent reacidification of internalized vesicles. The fraction of D/G VGAT-pH (green) released $(7.64 \pm 0.48 \%)$ is $\sim 40 \%$ larger than WT VGAT-pH $\left(5.48 \pm 0.51 \%\right.$, black), ${ }^{* *} p<0.01$ by two-tailed, unpaired $t$ test. C, AP-3 $\delta$ protein, but not AP- $1 \gamma$, or AP- $2 \alpha$, is specifically depleted by lentiviral expression of AP-3 $\delta 1$ shRNA, as shown by immunoblot analysis of hippocampal neuron extracts (left). Right, Quantified band intensity, averaged from two independent experiments, ${ }^{* * *} p<$ 0.0001, one-way ANOVA. D, AP-3 knockdown (open symbols) does not affect the fraction of WT VGAT-pH in the RRP. Conversely, AP-3 knockdown decreases the fraction of D/G VGAT-pH in the RRP to WT levels. $\boldsymbol{E}$, The fraction of WT VGAT in the RRP is insensitive to treatment with BFA. In contrast, the proportion of D/G VGAT-pH in the RRP reverts to WT levels after BFA treatment. $\boldsymbol{F}$, Treatment of AP-3 KD neurons with BFA has no additional effect on the fraction of D/G VGAT in the RRP. G, Similar results are observed with an alternate stimulus of $30 \mathrm{~Hz} 3 \mathrm{~s}$ to release the RRP. Expression of shRNA resistant $\delta 1$ rescues the AP-3 KD-mediated effect. Fluorescence changes upon RRP stimulation were measured in the presence $(\boldsymbol{A}, \boldsymbol{B})$ or absence $(\boldsymbol{D}-\mathbf{G})$ of bafilomycin. Data in $\boldsymbol{A}, \boldsymbol{B}, \boldsymbol{D}-\mathbf{G}$ are means $\pm \mathrm{SEM}$ of $\Delta \mathrm{F} / \mathrm{F}_{0}$ normalized to total fluorescence from at least 20 boutons per cs from 6 to $19 \mathrm{cs}$ from at least two independent cultures. 
cific sorting signals with specialized adaptor proteins, including clathrin APs, endophilin, and stonin 2 (Ferreira et al., 2005; Diril et al., 2006; Voglmaier et al., 2006). Acidic dileucine-like motifs have been shown to interact in vitro with heterotetrameric AP-1, AP-2, and/or AP-3 (Bonifacino and Traub, 2003; Kelly et al., 2008). Using in vitro binding assays, we show that the $\mathrm{N}$-terminus of VGAT interacts with AP-2. Further, mutation of $\mathrm{E}_{39}, \mathrm{E}_{40}$, and $\mathrm{F}_{44}$ within the dileucine-like motif substantially reduces this interaction. In support of the in vitro binding and live cell imaging data, endocytosis of VGAT is greatly slowed by depletion of AP-2. AP-2 knockdown increases the poststimulus cell surface levels of WT VGAT to levels similar to those observed for the dileucinelike motif mutants, which exhibit decreased AP-2 binding. These effects are reversed by rescue with an shRNA-resistant $\mu 2$ expressed in AP-2 KD neurons, corroborating the requirement and specificity of the interaction of VGAT with AP-2 at the nerve terminal.

By comparing the dileucine-like sequence of VGAT with other SV proteins, we noticed that a charged residue at position -6 of the dileucine-like motif is common (Erickson et al., 1994; Tan et al., 1998; Blagoveshchenskaya et al., 1999). Elimination of this charge by replacing $\mathrm{D}_{38}$ with glycine led to some of the most surprising observations in this study. The rate and extent of exocytosis differ between WT and D/G VGAT-pH, reflecting increased targeting of the mutant protein to readily releasable and recycling pool vesicles, at the expense of the reserve pool. We therefore investigated the molecular basis for increased sorting of D/G VGAT to the RRP, as this mutant could be a useful resource to understand the dynamic distribution of $\mathrm{SV}$ proteins among distinct vesicle pools. Remarkably, inhibition of the AP-3 pathway via knockdown of AP-3 $\delta 1$ or acute treatment with BFA restores D/G VGAT-pH responses to WT levels. Both biochemical and knockdown experiments thus point to a role for AP-3 in recycling of D/G VGAT-pH. Homology modeling suggests that the $\mathrm{D}_{38}$ residue would interact with a relatively nonconserved region of AP-2 and AP-3, just outside the highly conserved site of dileucine motif binding, providing a structural correlate for differences in D/G binding to AP-2 and AP-3 observed in GST pulldown assays (Kelly et al., 2008).

Although the role of AP-2 in SV recycling is well established, substantial SV endocytosis occurs in its absence (Gu et al., 2008; Kim and Ryan, 2009). Interaction with alternate adaptors may represent different modes of SV protein internalization (Faundez et al., 1998; Voglmaier et al., 2006; Glyvuk et al., 2010; Cheung and Cousin, 2012). Mice deficient in AP-1 exhibit impaired SV recycling and accumulate large endosomes in the nerve terminal (Glyvuk et al., 2010), whereas inhibition of AP-3 increases neurotransmitter release, perhaps by altering the distribution of vesicles among SV pools (Polo-Parada et al., 2001; Voglmaier et al., 2006). Here we find that a single amino acid change in VGAT alters its distribution across SV pools. Further, the increase in $\mathrm{D} / \mathrm{G}$ VGAT-pH in the RRP and recycling pool is dependent on AP-3. Acute AP-3 pathway inhibition mimics AP-3 knockdown, suggesting that changes take place locally at the nerve terminal. Increased D/G VGAT-pH in these pools would have the potential to increase neurotransmitter release. For glutamate, however, inhibition of AP-3 results in increased neurotransmitter release, consistent with an increase in the recycling pool (Voglmaier et al,, 2006). This opposite effect may be due to differences in the recycling of VGLUT and VGAT, as we note that similar mutations in the two transporters exhibit distinct phenotypes. Differences in excitatory/inhibitory balance were indeed noted in AP-3 knockout mice (Nakatsu et al., 2004). Nevertheless, the AP-3- dependent change in D/G VGAT-pH responses indicates that sorting signals in SV proteins engaging distinct molecular mechanisms can direct their targeting to different vesicle pools with distinct properties.

These studies provide a framework to understand how unique sorting sequences target individual SV proteins to pathways with different rates or destinations. In VAMP4, N-terminal dileucine motif-dependent endocytosis contributes to the generation of a pool of VAMP4-enriched vesicles that mediate asynchronous release during intense activity (Raingo et al., 2012). VAMP2 distribution also depends on residues in the cytosolic N-terminal domain. A polyproline domain in VAMP2 influences endocytosis (Hosoi et al., 2009), whereas the SNARE motif is required for protein recycling, and interaction with the endocytic adaptors AP180 and CALM (Koo et al., 2011). Moreover, a single point mutation (M46A) blocks endocytosis, abolishes axonal polarization, and prevents enrichment of VAMP2 at presynaptic vesicle clusters (Grote and Kelly, 1996; Sampo et al., 2003; Koo et al., 2011).

In conclusion, we performed a comprehensive analysis of trafficking signals present in the N-terminus of VGAT. Real-time imaging of VGAT-pH allowed us to uncover a wealth of information encoded within the amino acid sequence of the transporter, revealing that an atypical dileucine-like motif is critical for VGAT recycling at the nerve terminal by interaction with AP-2. Due to its relative simplicity, the N-terminal region of VGAT provides an excellent model for studying the interaction of an SV protein with clathrin adaptor proteins, and the physiological consequences of these interactions. Small manipulations within this region were sufficient to alter the synaptic localization, protein recycling and distribution of VGAT. We have also demonstrated that a single amino acid change $\left(\mathrm{D}_{38} / \mathrm{G}\right)$ can modulate VGAT recycling during stimulation and targeting to specific vesicle pools, and that this modulation occurs via an AP-3dependent mechanism. WT and D/G mutant VGAT-pH are valuable tools that will allow further analysis of different modes of protein sorting to SV pools with different propensities for release.

\section{References}

Ariel P, Ryan TA (2010) Optical mapping of release properties in synapses. Front Neural Circuits 4:18. CrossRef Medline

Armbruster M, Ryan TA (2011) Synaptic vesicle retrieval time is a cell-wide rather than individual-synapse property. Nat Neurosci 14:824-826. CrossRef Medline

Asensio CS, Sirkis DW, Edwards RH (2010) RNAi screen identifies a role for adaptor protein AP-3 in sorting to the regulated secretory pathway. J Cell Biol 191:1173-1187. CrossRef Medline

Balaji J, Ryan TA (2007) Single-vesicle imaging reveals that synaptic vesicle exocytosis and endocytosis are coupled by a single stochastic mode. Proc Natl Acad Sci U S A 104:20576-20581. CrossRef Medline

Balaji J, Armbruster M, Ryan TA (2008) Calcium control of endocytic capacity at a CNS synapse. J Neurosci 28:6742-6749. CrossRef Medline

Blagoveshchenskaya AD, Hewitt EW, Cutler DF (1999) Di-leucine signals mediate targeting of tyrosinase and synaptotagmin to synaptic-like microvesicles within PC12 cells. Mol Biol Cell 10:3979-3990. Medline

Bonifacino JS, Traub LM (2003) Signals for sorting of transmembrane proteins to endosomes and lysosomes. Annu Rev Biochem 72:395-447. CrossRef Medline

Burger PM, Hell J, Mehl E, Krasel C, Lottspeich F, Jahn R (1991) GABA and glycine in synaptic vesicles: storage and transport characteristics. Neuron 7:287-293. CrossRef Medline

Cheung G, Cousin MA (2012) Adaptor protein complexes 1 and 3 are essential for generation of synaptic vesicles from activity-dependent bulk endosomes. J Neurosci 32:6014-6023. CrossRef Medline

Craige B, Salazar G, Faundez V (2008) Phosphatidylinositol-4-kinase type II alpha contains an AP-3-sorting motif and a kinase domain that are both 
required for endosome traffic. Mol Biol Cell 19:1415-1426. CrossRef Medline

Diril MK, Wienisch M, Jung N, Klingauf J, Haucke V (2006) Stonin 2 is an AP-2-dependent endocytic sorting adaptor for synaptotagmin internalization and recycling. Dev Cell 10:233-244. CrossRef Medline

Donaldson JG, Finazzi D, Klausner RD (1992) Brefeldin A inhibits Golgi membrane-catalysed exchange of guanine nucleotide onto ARF protein. Nature 360:350-352. CrossRef Medline

Erickson JD, Varoqui H, Schäfer MD, Modi W, Diebler MF, Weihe E, Rand J, Eiden LE, Bonner TI, Usdin TB (1994) Functional identification of a vesicular acetylcholine transporter and its expression from a "cholinergic" gene locus. J Biol Chem 269:21929-21932. Medline

Faúndez V, Horng JT, Kelly RB (1998) A function for the AP3 coat complex in synaptic vesicle formation from endosomes. Cell 93:423-432. CrossRef Medline

Fei H, Grygoruk A, Brooks ES, Chen A, Krantz DE (2008) Trafficking of vesicular neurotransmitter transporters. Traffic 9:1425-1436. CrossRef Medline

Ferguson SM, Brasnjo G, Hayashi M, Wölfel M, Collesi C, Giovedi S, Raimondi A, Gong LW, Ariel P, Paradise S, O’toole E, Flavell R, Cremona O, Miesenböck G, Ryan TA, De Camilli P (2007) A selective activitydependent requirement for dynamin 1 in synaptic vesicle endocytosis. Science 316:570-574. CrossRef Medline

Ferreira LT, Santos MS, Kolmakova NG, Koenen J, Barbosa J Jr, Gomez MV, Guatimosim C, Zhang X, Parsons SM, Prado VF, Prado MA (2005) Structural requirements for steady-state localization of the vesicular acetylcholine transporter. J Neurochem 94:957-969. CrossRef Medline

Fykse EM, Fonnum F (1988) Uptake of gamma-aminobutyric acid by a synaptic vesicle fraction isolated from rat brain. J Neurochem 50:1237-1242. CrossRef Medline

Glyvuk N, Tsytsyura Y, Geumann C, D’Hooge R, Hüve J, Kratzke M, Baltes J, Böning D, Klingauf J, Schu P (2010) AP-1/sigma1B-adaptin mediates endosomal synaptic vesicle recycling, learning and memory. EMBO J 29: 1318-1330. CrossRef Medline

Gomes JR, Lobo AC, Melo CV, Inácio AR, Takano J, Iwata N, Saido TC, de Almeida LP, Wieloch T, Duarte CB (2011) Cleavage of the vesicular GABA transporter under excitotoxic conditions is followed by accumulation of the truncated transporter in nonsynaptic sites. J Neurosci 31: 4622-4635. CrossRef Medline

Grote E, Kelly RB (1996) Endocytosis of VAMP is facilitated by a synaptic vesicle targeting signal. J Cell Biol 132:537-547. CrossRef Medline

Gu M, Schuske K, Watanabe S, Liu Q, Baum P, Garriga G, Jorgensen EM (2008) Mu2 adaptin facilitates but is not essential for synaptic vesicle recycling in Caenorhabditis elegans. J Cell Biol 183:881-892. CrossRef Medline

Heilker R, Manning-Krieg U, Zuber JF, Spiess M (1996) In vitro binding of clathrin adaptors to sorting signals correlates with endocytosis and basolateral sorting. EMBO J 15:2893-2899. Medline

Hell JW, Maycox PR, Stadler H, Jahn R (1988) Uptake of GABA by rat brain synaptic vesicles isolated by a new procedure. EMBO J 7:3023-3029. Medline

Helms JB, Rothman JE (1992) Inhibition by brefeldin A of a Golgi membrane enzyme that catalyses exchange of guanine nucleotide bound to ARF. Nature 360:352-354. CrossRef Medline

Höning S, Sandoval IV, von Figura K (1998) A dileucine-based motif in the cytoplasmic tail of LIMP-II and tyrosinase mediates selective binding of AP-3. EMBO J 17:1304-1314. CrossRef Medline

Hosoi N, Holt M, Sakaba T (2009) Calcium dependence of exo- and endocytotic coupling at a glutamatergic synapse. Neuron 63:216-229. CrossRef Medline

Hua Z, Leal-Ortiz S, Foss SM, Waites CL, Garner CC, Voglmaier SM, Edwards RH (2011a) v-SNARE composition distinguishes synaptic vesicle pools. Neuron 71:474-487. CrossRef Medline

Hua Y, Sinha R, Thiel CS, Schmidt R, Hüve J, Martens H, Hell SW, Egner A, Klingauf J (2011b) A readily retrievable pool of synaptic vesicles. Nat Neurosci 14:833-839. CrossRef Medline

Jung N, Wienisch M, Gu M, Rand JB, Müller SL, Krause G, Jorgensen EM, Klingauf J, Haucke V (2007) Molecular basis of synaptic vesicle cargo recognition by the endocytic sorting adaptor stonin 2. J Cell Biol 179: 1497-1510. CrossRef Medline

Kelly BT, McCoy AJ, Späte K, Miller SE, Evans PR, Höning S, Owen DJ
(2008) A structural explanation for the binding of endocytic dileucine motifs by the AP2 complex. Nature 456:976-979. CrossRef Medline

Kim SH, Ryan TA (2009) Synaptic vesicle recycling at CNS snapses without AP-2. J Neurosci 29:3865-3874. CrossRef Medline

Koo SJ, Markovic S, Puchkov D, Mahrenholz CC, Beceren-Braun F, Maritzen T, Dernedde J, Volkmer R, Oschkinat H, Haucke V (2011) SNARE motif-mediated sorting of synaptobrevin by the endocytic adaptors clathrin assembly lymphoid myeloid leukemia (CALM) and AP180 at synapses. Proc Natl Acad Sci U S A 108:13540-13545. CrossRef Medline

Kwon SE, Chapman ER (2011) Synaptophysin regulates the kinetics of synaptic vesicle endocytosis in central neurons. Neuron 70:847-854. CrossRef Medline

Larimore J, Tornieri K, Ryder PV, Gokhale A, Zlatic SA, Craige B, Lee JD, Talbot K, Pare JF, Smith Y, Faundez V (2011) The schizophrenia susceptibility factor dysbindin and its associated complex sort cargoes from cell bodies to the synapse. Mol Biol Cell 22:4854-4867. CrossRef Medline

Lavoie N, Jeyaraju DV, Peralta MR 3rd, Seress L, Pellegrini L, Tóth K (2011) Vesicular zinc regulates the $\mathrm{Ca}^{2+}$ sensitivity of a subpopulation of presynaptic vesicles at hippocampal mossy fiber terminals. J Neurosci 31: 18251-18265. CrossRef Medline

Li H, Waites CL, Staal RG, Dobryy Y, Park J, Sulzer DL, Edwards RH (2005) Sorting of vesicular monoamine transporter 2 to the regulated secretory pathway confers the somatodendritic exocytosis of monoamines. Neuron 48:619-633. CrossRef Medline

Mani M, Lee SY, Lucast L, Cremona O, Di Paolo G, De Camilli P, Ryan TA (2007) The dual phosphatase activity of synaptojanin1 is required for both efficient synaptic vesicle endocytosis and reavailability at nerve terminals. Neuron 56:1004-1018. CrossRef Medline

Martens H, Weston MC, Boulland JL, Grønborg M, Grosche J, Kacza J, Hoffmann A, Matteoli M, Takamori S, Harkany T, Chaudhry FA, Rosenmund C, Erck C, Jahn R, Härtig W (2008) Unique luminal localization of VGAT-C terminus allows for selective labeling of active cortical GABAergic synapses. J Neurosci 28:13125-13131. CrossRef Medline

McIntire SL, Reimer RJ, Schuske K, Edwards RH, Jorgensen EM (1997) Identification and characterization of the vesicular GABA transporter. Nature 389:870-876. CrossRef Medline

Miesenböck G, De Angelis DA, Rothman JE (1998) Visualizing secretion and synaptic transmission with $\mathrm{pH}$-sensitive green fluorescent proteins. Nature 394:192-195. CrossRef Medline

Mohrmann R, Matthies HJ, Woodruff E 3rd, Broadie K (2008) Stoned B mediates sorting of integral synaptic vesicle proteins. Neuroscience 153: 1048-1063. CrossRef Medline

Morgenthaler FD, Knott GW, Floyd Sarria JC, Wang X, Staple JK, Catsicas S, Hirling H (2003) Morphological and molecular heterogeneity in release sites of single neurons. Eur J Neurosci 17:1365-1374. CrossRef Medline

Mullen GP, Grundahl KM, Gu M, Watanabe S, Hobson RJ, Crowell JA, McManus JR, Mathews EA, Jorgensen EM, Rand JB (2012) UNC-41/ stonin functions with AP2 to recycle synaptic vesicles in Caenorhabditis elegans. PLoS One 7:e40095. CrossRef Medline

Nakatsu F, Okada M, Mori F, Kumazawa N, Iwasa H, Zhu G, Kasagi Y, Kamiya H, Harada A, Nishimura K, Takeuchi A, Miyazaki T, Watanabe M, Yuasa S, Manabe T, Wakabayashi K, Kaneko S, Saito T, Ohno H (2004) Defective function of GABA-containing synaptic vesicles in mice lacking the AP-3B clathrin adaptor. J Cell Biol 167:293-302. CrossRef Medline

Nemani VM, Lu W, Berge V, Nakamura K, Onoa B, Lee MK, Chaudhry FA, Nicoll RA, Edwards RH (2010) Increased expression of alpha-synuclein reduces neurotransmitter release by inhibiting synaptic vesicle reclustering after endocytosis. Neuron 65:66-79. CrossRef Medline

Polo-Parada L, Bose CM, Landmesser LT (2001) Alterations in transmission, vesicle dynamics, and transmitter release machinery at NCAMdeficient neuromuscular junctions. Neuron 32:815-828. CrossRef Medline

Pond L, Kuhn LA, Teyton L, Schutze MP, Tainer JA, Jackson MR, Peterson PA (1995) A role for acidic residues in dileucine motif-based targeting to the endocytic pathway. J Biol Chem 270:19989-19997. CrossRef Medline

Pyle JL, Kavalali ET, Piedras-Rentería ES, Tsien RW (2000) Rapid reuse of readily releasable pool vesicles at hippocampal synapses. Neuron 28:221231. CrossRef Medline

Raingo J, Khvotchev M, Liu P, Darios F, Li YC, Ramirez DM, Adachi M, Lemieux P, Toth K, Davletov B, Kavalali ET (2012) VAMP4 directs syn- 
aptic vesicles to a pool that selectively maintains asynchronous neurotransmission. Nat Neurosci 15:738-745. CrossRef Medline

Ramirez DM, Khvotchev M, Trauterman B, Kavalali ET (2012) Vtila identifies a vesicle pool that preferentially recycles at rest and maintains spontaneous neurotransmission. Neuron 73:121-134. CrossRef Medline

Rapoport I, Chen YC, Cupers P, Shoelson SE, Kirchhausen T (1998) Dileucine-based sorting signals bind to the beta chain of AP-1 at a site distinct and regulated differently from the tyrosine-based motif-binding site. EMBO J 17:2148-2155. CrossRef Medline

Rodionov DG, Höning S, Silye A, Kongsvik TL, von Figura K, Bakke O (2002) Structural requirements for interactions between leucine-sorting signals and clathrin-associated adaptor protein complex AP3. J Biol Chem 277:47436-47443. CrossRef Medline

Rosenmund C, Stevens CF (1996) Definition of the readily releasable pool of vesicles at hippocampal synapses. Neuron 16:1197-1207. CrossRef Medline

Sagné C, El Mestikawy S, Isambert MF, Hamon M, Henry JP, Giros B, Gasnier B (1997) Cloning of a functional vesicular GABA and glycine transporter by screening of genome databases. FEBS Lett 417:177-183. CrossRef Medline

Salazar G, Love R, Werner E, Doucette MM, Cheng S, Levey A, Faundez V (2004) The zinc transporter ZnT3 interacts with AP-3 and it is preferentially targeted to a distinct synaptic vesicle subpopulation. Mol Biol Cell 15:575-587. CrossRef Medline

Sampo B, Kaech S, Kunz S, Banker G (2003) Two distinct mechanisms target membrane proteins to the axonal surface. Neuron 37:611-624. CrossRef Medline

Sandoval IV, Martinez-Arca S, Valdueza J, Palacios S, Holman GD (2000) Distinct reading of different structural determinants modulates the dileucine-mediated transport steps of the lysosomal membrane protein LIMPII and the insulin-sensitive glucose transporter GLUT4. J Biol Chem 275:39874-39885. CrossRef Medline

Sankaranarayanan S, Ryan TA (2000) Real-time measurements of vesicle-
SNARE recycling in synapses of the central nervous system. Nat Cell Biol 2:197-204. CrossRef Medline

Sankaranarayanan S, Ryan TA (2001) Calcium accelerates endocytosis of vSNAREs at hippocampal synapses. Nat Neurosci 4:129-136. CrossRef Medline

Santos MS, Barbosa J Jr, Veloso GS, Ribeiro F, Kushmerick C, Gomez MV, Ferguson SS, Prado VF, Prado MA (2001) Trafficking of green fluorescent protein tagged-vesicular acetylcholine transporter to varicosities in a cholinergic cell line. J Neurochem 78:1104-1113. CrossRef Medline

Santos MS, Li H, Voglmaier SM (2009) Synaptic vesicle protein trafficking at the glutamate synapse. Neuroscience 158:189-203. CrossRef Medline

Scheuber A, Rudge R, Danglot L, Raposo G, Binz T, Poncer JC, Galli T (2006) Loss of AP-3 function affects spontaneous and evoked release at hippocampal mossy fiber synapses. Proc Natl Acad Sci U S A 103:16562-16567. CrossRef Medline

Tan PK, Waites C, Liu Y, Krantz DE, Edwards RH (1998) A leucine-based motif mediates the endocytosis of vesicular monoamine and acetylcholine transporters. J Biol Chem 273:17351-17360. CrossRef Medline

Theos AC, Tenza D, Martina JA, Hurbain I, Peden AA, Sviderskaya EV, Stewart A, Robinson MS, Bennett DC, Cutler DF, Bonifacino JS, Marks MS, Raposo G (2005) Functions of adaptor protein (AP)-3 and AP-1 in tyrosinase sorting from endosomes to melanosomes. Mol Biol Cell 16: 5356-5372. CrossRef Medline

Voglmaier SM, Edwards RH (2007) Do different endocytic pathways make different synaptic vesicles? Curr Opin Neurobiol 17:374-380. CrossRef Medline

Voglmaier SM, Kam K, Yang H, Fortin DL, Hua Z, Nicoll RA, Edwards RH (2006) Distinct endocytic pathways control the rate and extent of synaptic vesicle protein recycling. Neuron 51:71-84. CrossRef Medline

Willox AK, Royle SJ (2012) Stonin 2 is a major adaptor protein for clathrinmediated synaptic vesicle retrieval. Curr Biol 22:1435-1439. CrossRef Medline 